American Journal of Agricultural and Biological Sciences 7 (2): 150-172, 2012

ISSN 1557-4989

(C) 2012 Science Publications

\title{
Agro-Process Intensification through Synthetic Rhizosphere Media for Nitrogen Fixation and Yield Enhancement in Plants
}

\author{
${ }^{1,2}$ Akay, G. and ${ }^{1}$ D.R. Burke \\ ${ }^{1}$ Process Intensification and Miniaturisation Centre, \\ Faculty of Science Agriculture and Engineering, \\ ${ }^{2}$ The Institute of Stem Cell Biology and Regenerative Medicine, \\ Newcastle University, Newcastle upon Tyne NE1 7RU, UK
}

\begin{abstract}
Problem statement: In order to combat global warming and the emerging Food, Energy and Water shortages (FEWs), several approaches have been adopted, including genetic engineering and farming practices. Biomass based energy technology will further stress food and water resources and hence novel holistic approaches to FEWs should be designed. Approach: A novel technique (Agro-Process Intensification, A-PI) which simultaneously addresses FEWs in general and food production in particular was described. The technique was based on the enhancement of multiple interactions between plant roots, water, nutrients and bacteria using soil additives in the form of microbioreactors which allow plant root growth through them thus generating a micro-environment acting as a Synthetic Rhizo Sphere (SRS). The SRS-media was a nano-structured micro-porous crosslinked, elastic, ionic and highly hydrophilic polymer, facilitating the efficient use of water and nutrients as well as nitrogen fixation in legumes. Results: SRS media, with or without bacteria, was prepared, characterized and used in greenhouse experiments. Grass, for which the enhancement was well above $200 \%$ under water stress, was used to evaluate the mechanism of A-PI. The pea plant was used to demonstrate the intensification achievable by biologically active micro-bioreactors in which nitrogen fixing bacteria, Rhizobia, were supported within the SRS-media. Biologically active SRS-media enhanced the plant root infection by nitrogen fixing bacteria and increased both crop yield (ca. 70\%) and mineral content. Conclusion/Recommendations: A-PI is achieved principally through the elimination of the random nature of the root/water/nutrient/microorganism interactions. The association of SRS-media with plant roots provides a unique and efficient delivery technique for water and nutrients while protecting beneficial bacteria within the SRS for infection enhancement. Focus on the understanding of the molecular mechanisms of yield enhancement and SRS formation as well as performance in field trials, especially in marginal land under water and nutrient stress, are recommended.
\end{abstract}

Key words: Abiotic stress, agro-process intensification, nitrogen fixation, nutrient stress, polyHIPE polymer, slow release fertilizer, soil additives, synthetic rhizosphere, water stress

\section{INTRODUCTION}

Objectives of agro-process intensification: Technology led increases in crop yield achieved during 1970-1990 has not been replicated since then and the rate of enhancement has been falling (Conway and Toenniessen, 1999). Increasing demand for food as well as energy crops poses huge challenges for the sustainability of terrestrial ecosystems. Current trends in agriculture add to these concerns. They include, diminishing returns of fertilizer application, water and temperature stress, global warming and rapid approach to climateadjusted genetic yield potential ceiling which indicates that there is a lack of large exploitable 'yield gap' in agriculture (Tilma et al., 2002).
In order to combat these challenges, several strategies are currently under development including genetic engineering (Wang et al., 2007; Ashraf et al., 2009). In this present study we disclose a new method of dealing with water and fertilizer stress and the possibility of establishing an engineered ecosystem through the generation of Synthetic Rhizosphere (SRS) in combating abiotic stresses (Mittler, 2006) through plant root systems. The efficient use of water and nutrients or indeed enhancement of biological nitrogen fixation by plants is achieved by associating plant roots with SRS-media used as a soil additive. SRS-media should facilitate more efficient interactions between water, nutrients, bacteria and plant roots on a large scale while acting as water and nutrient collector from

Corresponding Author: Akay, G. Process Intensification and Miniaturisation Centre, Faculty of Science Agriculture and Engineering, Newcastle University, Newcastle upon Tyne NE1 7RU (UK) 
soil and diverting them to plant roots. This technique differs fundamentally from other biomass/crop enhancement techniques using soil conditioners or slow release fertilizers or inter-cropping or biological nitrogen fixation because, in the present technique, the SRS-media is associated with the plant roots thus the delivery of the nutrients, water and the infection of roots (leading to nodule formation for biological nitrogen fixation by bacteria in legumes) is direct and concentrated at the root hairs. Furthermore, SRS-media can also deliver other benefits to plants such as biocontrol of soil-borne diseases and enhancement of mineral uptake and micronutrients the deficiency of which results in severe reductions in crop yield (Marschner et al., 1996; Cakmak, 2000). The technique presented here can be viewed as Process Intensification (PI) in agriculture (AgroProcess Intensification, A-PI) since the technique delivers large enhancement in biomass and crop yield and its principles are in common with process intensifications in biological and chemical processing (McKetta, 1995).

Recently, in an international expert report to combat food shortages, it has been proposed (Glover et al., 2010) that using perennial crops such as wheat would enhance higher yields because of the deeper root association which results in better water utilisation. Therefore, the use of SRS-media polymers in perennial crops as well as those crops that can fix nitrogen from air (i.e., legumes) or indeed in energy crops becomes sustainable and cost effective as the root association between the plant and SRS-media can continue for a long time.

Process Intensification (PI): Process Intensification (PI) evolved as a new chemicals processing philosophy aimed at reducing size of chemical plants, in order to reduce capital and operating costs while eliminating parasitic side reactions and promoting novel processing pathways (McKetta, 1995; Kumar and Nigam, 2012). PI can be achieved through two basic routes. Firstly, through the enhancement of heat and mass transfer by operating at extreme thermodynamic states (pressure, temperature, concentration) or by enhancing Transfer Area Density area (TAD, surface area per unit volume), imposition of external forces such as centrifugal, ultrasonic, electric/electro-magnetic and microwave irradiation as well as through the reduction of diffusion/conduction pathways in heat/mass transfer operations. Such intensifications are known as Physical PI. Miniaturization (McKetta, 1995; Wirth, 2008; Hessel et al., 2009; Mawatari et al., 2011) in the form of micro-reactors, also achieves PI since the diffusion/conduction paths are drastically reduced and the uniformity of the processing field enhances selectivity. In the second route for PI, the miniaturization of the processing volume (reactor) is essential (to promote interactions between reactants and catalysts) because the intensification is due to a phenomenon resulting from the complex interactions between the intensification field, fluid transport, catalyst (or biocatalyst), walls of micro-environment and reactants and products, as postulated by McKetta (1995). These interactions lead to Chemical Process Intensification (C-PI) which can be 1-3 orders of magnitude compared with the existing technology (McKetta, 1995; Akay et al., 2012). This type of PI is known as Phenomenon-based PI (McKetta, 1995). The application of microreactors to bioprocessing such as biological remediation, enzyme or drug production or indeed tissue engineering, resulted in BioProcess Intensification (B-PI) with several fold enhancement (typically 3-30 fold reported) compared with the classical technology (McKetta, 1995; Akay, 2011; 2012). The underlying driving force for B-PI (to date) is 'size dependent confinement phenomenon' in which the behaviour of microorganisms or mammalian cells is found to depend on the size of the microenvironment in which they are grown in 3-Dimensional support (McKetta, 1995; Akay and Burke 2010; Akay et al., 2002; Bokhari et al., 2003; Akay et al., 2004; Akay et al., 2005; Lens and Lens, 2005; Galan and Valle, 2006; Bokhari et al., 2005). The microenvironment dependent behaviour includes the enhancement of microorganism/cell viability, proliferation, selectivity, productivity (due to the modification of metabolic pathways), differentiation and even morphology of microorganisms and cells (McKetta, 1995).

A Model for AgroProcess Intensification (A-PI): Although irrigation/water flow is the most effective method for transporting bacteria and nutrients to the roots (Bahme and Schroth, 1987) water flow also results in the dispersion of the bacteria and nutrients throughout the soil thus reducing the local bacterium and nutrient concentrations in soil and creating a large water and bacterium gradient across rhizosphere and bulk soil. Furthermore, the continual dispersion of the bacteria can result in the breakdown of colonies, quorum signalling, collective activity and eventual bacterial depletion of the soil as a result of hostile soil environment. These events result in reduced probability of root bacterial infection and nutrients and water loss. Therefore, like water, nutrients, fertilizers and soil bacteria are also replaced using different methods, including the coating of the seeds with a bacterial broth. Furthermore, the root-bacterium interaction area per unit volume of the plant root region is small. The root surface area per unit volume of soil can be considered to be a Transport Area Density (TAD) which is important in many heat and mass transfer processes (McKetta, 1995). In chemical and biochemical 
processes, TAD can be enhanced by using microreactors with high accessible surface area for catalysis or heat and mass transfer (McKetta, 1995; Wirth, 2008; Hessel et al., 2009; Akay et al., 2010; Kumar and Nigam, 2012).

The most important biochemical transformations take place not in bulk soil but in the rhizosphere where the interactions between plant roots, microorganisms and soil are fundamental importance to plant growth. The ability to secrete a vast array of compounds into the rhizosphere is one of the most remarkable metabolic features of plant roots, with nearly $5-21 \%$ of all photosynthetically fixed carbon being transferred to the rhizosphere through root exudates (Walker et al., 2003). Nevertheless, the rhizosphere is open to bulk soil and pathogenic microorganisms which reduce their biological efficiency. The current technique described herein brings together water, nutrient, plant roots and where applicable bacterium within the pores of the interaction-media so that the effective diffusion path for mass transfer is reduced and TAD is increased while the bacterium concentration in 3D culture within the pores is also increased. We can therefore describe the interaction media provided by the soil additives as Synthetic Rhizosphere (SRS)-media. Furthermore, the pores of the SRS-media act as a protective microenvironment for the bacteria while acting as water /nutrient collector in soil and water/nutrient source for the plant roots growing through its pores. Increased bacterial concentration within this SRSmedia enhances bacterial survival and quorum signalling as well as protection of root extrudes, thus enhancing plant-bacterium symbiosis.

Apart from acting as a support for bacteria, the physical-chemical structure of the microreactors must allow the rapid adsorption and storage of water and nutrients from the soil and release them gradually to the plant roots. To achieve these functions, the roots should penetrate into the SRS-media. Therefore these conditions restricts the chemical and physical structure of SRS-media used in A-PI. It is also possible to design SRS-media in order to deliver a specific function such as water or nutrient collection/storage, bacterial support or delivery of bioscides.

Finally, it is very important to note that, for the current method to work, it is essential that there is an inherent mechanism for the roots to grow towards the SRS-media which contains more water and nutrients than the bulk of the soil. Without such driving force, root and SRS-media interactions will be ineffective at low levels of SRS-media concentration in soil. Recent studies indicate that there is indeed a bias root growth present towards the source of water and fertilizer through hydrotropism and chemotropism respectively
(Takahashi et al., 2003; Eapen et al., 2005; Sbrana and Giovannetti, 2005; Leitner et al., 2010).

Significance of AgroProcess intensification: AgroProcess Intensification is important under abiotic stresses because of global warming as a result of which water and nitrogen stress in agriculture will increase while the increased demand for biomass, food and fertilizers will make any biomass based energy/chemicals feedstock technologies unsustainable. Below, we review the currently available technology in plant and crop yield enhancement to illustrate the similarities, differences and possible synergistic extensions with the proposed technique of A-PI.

Super-Absorbent Polymers (SAPs): The greatest potential for polymers in agricultural and horticultural applications is likely to be in soils of low water holding capacity and in semi-arid regions. In many semi-arid countries, irrigation of crops is carried out using low quality water therefore exacerbating soil salinity. Super-absorbent polymers and hydrogels have been reported to absorb up to 2400 times their weight in deionized water even under pressure. The application of hydrogels has been shown to supply water to growing crops, reduce the impact of water deficit stress and to reduce irrigation requirement, lower the death rate of plants, improve fertiliser retention in soils and increase plant growth (Mohana et al., 2003; El-Rehim et al., 2004; Liu et al., 2004; 2007; Chu et al., 2008). Plant growth benefits in terms of plant height, leaf width, total dry weight and increased length of time before the plant begins to wilt have been observed. This is achieved via the influence of the polymer or hydrogel on a range of characteristics, e.g., soil permeability, density, structure, texture, compaction, aeration, erosion and microbial activity, as well as affecting water runoff, evaporation and infiltration rates (El-Rehim et al., 2004). However, due to poor cross-linking (which allows high water retention and swelling), hydrogels are readily degraded and washed away, requiring replenishment. An excellent overview of polymeric soil additives and their function is available (Puoci et al., 2008).

Slow release fertilizers: Although fertiliser produce high yields and quality of agricultural crops (Jorgensen et al., 2005), excess application and poor use efficiency often leads to leaching and run-off, which results in eutrophication of water systems due to 'algal blooms' in lakes and 'red tides' in estuaries (Chen and Zhu, 2002). It is estimated that $50-70 \%$ of the applied fertilizer can be lost to the environment (Abraham and Pillai, 1996). To help increase the efficiency of fertiliser 
use, slow- and controlled-release systems have been developed to release the fertiliser to the plants at a rate at which it can be utilised, therefore minimising loss to the environment through leaching and run-off (Liu et al., 2007; Chu et al., 2008; Abraham and Pillai, 1996; Fernandez-Escobar et al., 2004).

Bacterial inoculation: The desired effects of inoculants on plant growth include nitrogen fixation in legumes, biocontrol of soil-borne diseases, the enhancement of mineral uptake, weathering of soil minerals and nutritional or hormonal effects. Inoculation of soil with rhizobacteria results in the infection of roots of compatible plants to form effective nodules. A variety of methods can be used to inoculate crops, with the most common being to coat the seed with powdered inoculants which can then infect the seed as it begins to germinate. Depending on the soil type, host plant and bacteria, the dispersion of rhizobacteria from the point of inoculation towards the roots will depend on either the active motility of the bacteria and the passive movement of bacteria in water or on vectors for bacterial transport (Benizri et al., 2001). However, studies examining pea root colonisation by Pseudomonas fluorescens (Bowers and Parke, 1993) and also potato root colonisation by Pseudomonas strains (Bahme and Schroth, 1987) indicate that irrigation and water flow is the most effective method for transporting bacteria to the roots; indicating that under water stress, it will be ineffective.

A number of Rhizobium strains can stimulate plant growth without nodule formation, via promoting nutrition, accelerating mineralisation processes, or by protecting against pathogenic soil micro-organisms (Benizri et al., 2001). However, the yield response in such cases is obviously less than where nitrogen is fixed. Pea (Pisum sativum) crops are an important source of protein in human diets, as well as providing forage for animal feed (Santalla et al., 2001). Peas are nodulated by Rhizobium leguminosarum biovar viciae $(R l v)$ which is commonly found in European arable soils (Mutch and Young, 2004). All Rhizobia show host specificity to some extent and $R l v$ is capable of nodulating all species in the tribe Vicieae, which includes the genera Vicia, Lathyrus, Pisum and Lens (Allen, 1981). Usually in legume-Rhizobium symbiosis it is host specificity that determines the attachment of Rhizobium and Bradyrhizobium species to the legume roots, but studies show that for the Rhizobium-pea system, it is the conditions under which the rhizobia are grown that strongly influences the attachment to roots (Rhijn and
Vanderleyden, 1995). This is believed to be due to low inoculation efficiency of the $R l v$ strains and poorly studied strain-cultivar specificity (Fesenko et al., 1995).

The attachment of Rhizobium leguminosarum to pea root hairs is known to be dependent on the incubation $\mathrm{pH}$ and growth phase, with the optimal attachment being at $\mathrm{pH} 7.5$ and with bacteria in the early stationary phase of growth (Smit et al., 1986). The amount of N2 that is fixed via the Rhizobium and pea (Pisum sativum L.) symbiosis ranges from $52-77 \mathrm{~kg} \mathrm{~N}$ ha-1 (Stacey et al., 1992).

Mixed bacterial inoculants: Mixed inoculants (combination of microorganisms) that interact synergistically can provide nutrients, remove inhibitory products and stimulate each other through physical or biochemical activities that may enhance some beneficial aspects of their physiology, like nitrogen fixation. An example of mixed bacterial inoculants is Azosipirillum which can associate with PolysaccharideDegrading Bacteria (PDB), where PDB produce degradation and fermentation products used by Azosipirillum as a carbon source, which in turn provides PDB with nitrogen (Al-Nahidh and Gomah, 1991; Halsall, 1993; Bashan, 1998).

Other examples include the association between Azosipirillum and Bacillus that degrades pectin, Azosipirillum and Cellulomonas that degrade cellulose and Azosipirillum and Enterobacter coacae that ferments glucose (Bashan, 1998). Azosipirillum is also considered to be a Rhizobium-helper, stimulating nodulation, nodule activity, plant metabolism, all of which stimulate plant growth variables and plant resistance to unfavourable conditions. Beneficial combination of Azosipirillum or Azotobacter with Streptomyces and Azosipirillum with Phialophora radicola (fungal control agent) are well documented (Bashan, 1998).

Mixed inoculation with diazotrophic bacteria and arbuscular-mycorrhizal fungi creates synergistic interactions that may result in significant increase in growth, in the phosphorous content in plants, enhanced mycorrhizal infection and an enhancement in the uptake of mineral nutrients such as phosphorus, nitrogen, zinc, copper and iron (Solano et al., 2008). Mixed inoculants are also effective to increase salt tolerance (Waller $e t$ al., 2000; Khaosaad et al., 2007).

Inter-cropping: Intercropping utilizes nature's integration technique in polyculture where the outputs from one plant are utilized by others. In intercropping, the productivity of the main crop is enhanced by the presence of added crops. The mechanisms of enhanced productivity of the primary crop through intercropping are numerous (Papendick et 
al., 1976; Bashan, 1998; Stoop et al., 2002), including enhanced biodiversity and crop yield.

\section{MATERIALS AND METHODS}

\section{Materials:}

Fertilizers: John Innes Loam-Based Compost No.3 was used for soil. Horticultural sand was supplied by Moorbank Gardens, Newcastle University, Newcastle upon Tyne, UK. Fertilizer, Nitram was supplied by Terra Nitrogen, Teeside, UK. Liquid fertiliser MiracleGro () Pour and Feed was supplied by The Scotts Company (UK) Limited, Godalming, Surrey, UK.

Bacterium, culture and seeds: Agar, Mannitol, Yeast and Sodium Carbonate were all obtained from Sigma Aldrich, Gillingham, Dorset, UK. Bacterium (Rhizobium leguminosarum) was obtained in vacuum dried form from Deutsche Sammlung von Mikroorganismen und Zellkulturen GmbH (DSMZ), Braunschweig, Germany. Perennial rye grass was of the Superstar Variety and purchased as seeds from Agriculture, Environment and Fisheries Department, London, UK. Peas (Pisum sativum L.) were the Kelvedon Wonder, dwarf versatile variety, supplied by Johnsons of Newmarket, Suffolk, UK.

Materials for the preparation of symbiosis-media polymers: All chemicals were reagent grade. Monomers (styrene and 2-ethyl hexyl acrylate), cross-linking agent (divinyl benzene, DVB), polymerization initiator (potassium per sulphate), sulphonation agent $(0.97 \mathrm{~g}$ sulphuric acid/gram solution), neutralization agent ( $5 \mathrm{~N}$ ammonium hydroxide) were all supplied by Aldrich.

Preparation on synthetic rhizosphere media polymers: The SRS-media polymer is a nanostructured crossed linked hydrophilic elastic ionic micro-porous material, generically known as PolyHIPE Polymers (PHPs) which are prepared through a High Internal Phase Emulsion (HIPE) polymerization and subsequent functionalization route as disclosed (Narkis, and Rosenzweig, 1995; Akay, 1998; Akay, 2011; Akay and Vickers, 2010; Akay et al., 2002; Wang and Holladay, 2005; Burke et al., 2010). Various aspects of the preparation and applications of PolyHIPE Polymers are also available (McKetta, 1995; Akay, 2011; 2012; Akay et al., 2002; Bokhari et al., 2003; Akay et al., 2004; Akay et al., 2005; Wang and Holladay, 2005; Lens and Lens, 2005; Galan and Valle, 2006; Bokhari et al., 2005; Brebbia et al., 2011; Akay et al., 2010; Akay and Vickers, 2010; Erhan et al., 2004). The preparation of functionalised PHPs has 3 stages (1) Stable HIPE formation; (2) Polymerisation and (3) Functionalization.
Preparation of high internal phase emulsions: Composition of phases: The aqueous phase of HIPE consists of deionised water, an initiator of polymerisation (potassium persulphate) and $0.05 \mathrm{~g}$ sulphuric acid/g solution as the nano-structuring agent. Volume fraction of aqueous phase (phase volume) was 0.90 . Oil phase of HIPE consists of monomers, cross-linking agent and non-ionic surfactant. Oil phase composition is:

- $\mathrm{S}=$ Weight fraction of styrene in the oil phase $=$ 0.76-X (g styrene/g oil phase)

- $\mathrm{X}=$ Co-monomer (2-ethylhexyl acrylate) concentration (g co-monomer/g oil-phase)

- $\quad$ Cross-linking agent (divinyl benzene, $\mathrm{DVB})=0.1$ g DVD/g oil phase

- Non-ionic surfactant (sorbitan monooleate, Span $80)=0.14 \mathrm{~g}$ surfactant/g oil-phase

- Two types of polymers were obtained depending on the value of $X$. They are

- Cross-linked styrene homopolymer (PS-PHP) $X=0$

- Cross-linked styrene-2-ethylhexyl acrylate copolymer (PS/EHA-PHP): $\quad \mathrm{X}=0.20 \mathrm{~g}$ comonomer/g oil-phase

Emulsification: The oil and aqueous phases were prepared at room temperature. The emulsification was carried out at room temperature in a closed vessel. The oil phase was placed into the mixing vessel (internal diameter $12 \mathrm{~cm}$ ) just before the start of the emulsification and then the aqueous phase was dosed into the oil phase, via a peristaltic pump into the mixing vessel, whilst mixing which was achieved via 3 flat paddles $(9 \mathrm{~cm}$ diameter), stacked at right angles. Bottom impeller was as close to the bottom of vessel as possible and the other impellers are spaced so that when all of the aqueous phase was dosed, the top impeller was immersed $1 \mathrm{~cm}$ below the emulsion surface. Dosing of the aqueous phase into the mixing vessel was conducted from the top of the vessel in such a way that the aqueous phase fell as a film on the vessel wall so that the impingement of the liquid did not create a jet mixing. The dosing time was $5 \mathrm{~min}$ and the impeller speed was $300 \mathrm{rpm}$ during dosing. After the completion of dosing, the emulsion was homogenised by mixing for a period of $1 \mathrm{~min}$ at $300 \mathrm{rpm}$ impeller speed. Volume of the oil phase was $25 \mathrm{~mL}$ and that of the aqueous phase was 225 $\mathrm{mL}$. Details and theoretical background of the method are available (Narkis and Rosenzweig, 1995; Akay, 1998).

Polymerization of HIPE to obtain PolyHIPE Polymers (PHPs): Styrene or styrene/2-ethylhexyl acrylate monomer high internal phase emulsion was 
polymerized at $60^{\circ} \mathrm{C}$ for $8 \mathrm{~h}$ in sealed polypropylene cylindrical tubes $(2.3 \mathrm{~cm}$ diameter). The presence of small amount of sulphuric acid creates instability which is however not sufficient to cause full phase separation. This instability causes nano-structure formation in the walls of PHP during polymerisation. After polymerization, it was functionalized. High water adsorption capacity and elasticity are required in the present application. Elasticity can be achieved either by the presence of ethyl 2ethylhexyl acrylate in the copolymer chains (i.e., PS/EHA Copolymer) or by swelling upon water adsorption when cross-linked polystyrene is transformed into highly hydrophilic polymer by sulphonation. Upon the removal of water, sulphonated PHP recovers its original rigidity. Although PS/EHA PHP is elastic but it is also hydrophobic. It can be rendered hydrophilic by sulphonation. After polymerization, PHP samples were cut into $4 \mathrm{~mm}$ thick disks (which swell to $5 \mathrm{~mm}$ during sulphonation and subsequent water adsorption) and they were then washed with distilled water for $2 \mathrm{~h}$ in excess water while changing water twice. Then PHP disks were dried in a fume cupboard for $24 \mathrm{~h}$ before sulphonation.

\section{Functionalization of Poly HIPE polymers: Sulphonation and neutralization: After} polymerisation, washing and air drying as described above, polymer disks were soaked in $0.97 \mathrm{~g}$ sulphuric acid/g solution for a period of $2 \mathrm{~h}$ and then irradiated with microwaves using a Panosonic kitchen microwave oven $(1000 \mathrm{~W})$. However, microwave ovens are well known for their irregular distribution of irradiation, which usually results in the development of hotspots within the sample. Hotspots can lead to charring of the polymer, so as a quality control measure, the samples were irradiated at intervals of $30 \mathrm{sec}$ after which the discs were allowed to cool for $60 \mathrm{sec}$ and were turned upside down and randomly distributed into new positions on the microwave dish. Irradiation was continued until total irradiation time was typically 150 sec for 14 discs, by which time the polymer had swelled into a soft, spongy structure. Under these conditions, the degree of sulphonation was ca. 70\%. Prolonged sulphonation does not enhance degree of sulphonation but increases elemental carbon formation. Therefore, this irradiation time at this power rating was found to be optimum. It is also possible to sulphonate using just 0.1 $\mathrm{g}$ sulphuric acid/g aqueous phase solution but the water uptake capacity of these PHPs are lower (McKetta, 1995; Akay et al., 2010).

After sulphonation, PHP samples were washed thoroughly with water to remove excess acid and subsequently it was neutralized using $5.0 \mathrm{~N}$ ammonium hydroxide solution followed by further water washing to ensure no access ammonia is left in the polymer. These polymers were dried, cut into cubical pieces measuring approximately $5 \times 5 \times 5 \mathrm{~mm}$ (volume ca. 125 $\mathrm{mm}^{3}$ ) and stored for future plant growth experiments.

Preparation for greenhouse experiments with grass: We used rye grass and pea as our two model plants to test the effectiveness of the SRS-media in enhancing plant growth and crop yield and to understand the mechanism of this process. The purpose of the experiments with grass includes: (1) To understand the level of plant biomass yield under water and fertilizer stress conditions using different forms of soil additive and SRS-media polymers, (2) To understand the mechanism of biomass yield enhancement.

Preparation for grass planting: $75 \mathrm{~mL}$ air dried and sieved horticultural soil was mixed with $25 \mathrm{~mL}$ horticultural sand and $200 \mathrm{~g}$ of the resulting mixture of soil was placed into $8 \mathrm{~cm}$ diameter pots. The soil was $6 \mathrm{~cm}$ deep in the pot and reached the lower lip of the pot, where the diameter was $7 \mathrm{~cm}$, the surface area 38.5 $\mathrm{cm}^{2}$ and was $1.5 \mathrm{~cm}$ below the upper lip of the pot. SRS-media $(1.0 \mathrm{~g}$ per plant pot containing $200 \mathrm{~g}$ soil) was thoroughly mixed into the soil before the addition of $5 \mathrm{~g}$ of perennial rye grass seed which was spread evenly over the soil surface. A control treatment without polymer was also used. The seeds were covered with a thin layer of soil until level with the lower lip of the pot and then given $40 \mathrm{ml}$ of tap water. The pots were randomly distributed within a $2 \times 2 \mathrm{~m}^{2}$ area of greenhouse.

After 21 days the grass was cut at the upper lip level of the pot, $1.5 \mathrm{~cm}$ above the soil surface. The grass was then immediately weighed to determine the fresh weight before being placed in an oven at $60^{\circ} \mathrm{C}$ for $72 \mathrm{~h}$ and reweighed to determine the dry weight. Growth experiments to test nutrient depletion and fertiliser utilisation were continued for second and third harvests after 42-63 days respectively. After the final harvests, roots were removed and carefully washed in water in order to reveal the PHP root interactions.

Fertilizer application: Nitram fertiliser, containing $0.345 \mathrm{~g}$ nitrogen $/ \mathrm{g}$ fertilizer, was applied at a dose of $0.1 \mathrm{~g}$ fertiliser dissolved into $25 \mathrm{~mL}$ water and given to each pot at the planting stage. The liquid fertilizer, Miracle-Gro (MG) was used as per the manufacturer's guidelines, with each pot receiving an undiluted application of $25 \mathrm{~mL}$ at the planting stage. Neither Nitram nor Miracle-Gro fertilizer was reapplied after the initial planting. 
Preparation for greenhouse experiments with pea: Cubical sulphonated-neutralised-styrene (spongy) PolyHIPE Polymer (SNS-PHP) with pore size of 150 $\mu \mathrm{m}$, measuring ca. $5 \times 5 \times 5 \mathrm{~mm}$ were used as the SRSmedia. Daily watering regime was employed. No additional fertilizer was added to the soil. Biologically active SNS-PHPs were prepared as described below.

Preparation of broth and agar medium: The Rhizobium containing SRS-media was prepared using the method and ingredients recommended by the supplier of the bacterium. Firstly we prepared a liquid growth media for the bacteria. Air dried and sieved (through a $2 \mathrm{~mm}$ sieve) soil ( $40 \mathrm{~g}$ ) was mixed with 100 $\mathrm{mL}$ deionised water and $0.1 \mathrm{~g}$ sodium carbonate. After equilibration of the dispersion and sedimentation of the solids, liquid extract was recovered. To prepare $500 \mathrm{~mL}$ of broth medium, $400 \mathrm{~mL}$ of deionised water was mixed with $100 \mathrm{~mL}$ of the soil extract, $5 \mathrm{~g}$ of Mannitol and $0.5 \mathrm{~g}$ of yeast. The resulting dispersion was separated into $100 \mathrm{~mL}$ containers and autoclaved for one hour at $121^{\circ} \mathrm{C}$ and stored as the broth medium for bacterial growth. To prepare $500 \mathrm{~mL}$ of the solid agar medium, the above procedure was followed: $100 \mathrm{~mL}$ of the soil extract was added to $400 \mathrm{~mL}$ distilled water with $5 \mathrm{~g}$ of Mannitol, $0.5 \mathrm{~g}$ of yeast and 7.5 gram Agar and the resulting dispersion was autoclaved for one hour at $121^{\circ} \mathrm{C}$. The dispersion was then poured into sterilised Petri dishes within a sterilised fume cupboard, allowed to cool and set for 30 min before stacked and stored whilst the bacteria were prepared for seeding.

Preparation of bacteria for incubation: The Rhizobium leguminosarum were supplied in a vacuum dried pellet form. To prevent contamination of the samples, the entire process of preparing the $R$. leguminosarum, from the initial opening of the bacteria container to inoculation of the agar plates prepared above, was carried out within a sterilised fume cupboard. To disperse the dried pellet of Rhizobium, 5 $\mathrm{mL}$ of the broth medium (as prepared above) was added to the pellets and left to equilibrate for $30 \mathrm{~min}$. A sterile loop is then placed into the broth medium containing bacterial and streaked across the prepared agar plate to produce isolated colonies during incubation. A fresh sterile loop is used for each streak on each agar plate, which is kept sealed with a lid immediately before and after inoculation. The plates are then stacked, labelled and sealed with two strips of adhesive tape crossing over the top and bottom of the pile. The dishes were placed upside down within an incubator set to $26^{\circ} \mathrm{C}$ and left to allow the $R$. leguminosarum to grow for 7 days until clear individual colonies had developed. A selection of individual colonies were then inoculated onto fresh plates and incubated again, to ensure that no contaminants had got onto any plates.
Preparation of bacterial dispersion in broth medium for inoculation of PHPs: From the second set of incubated agar plates, a single colony was collected on a sterile loop and placed into one of the five different containers of $100 \mathrm{~mL}$ fresh autoclaved broth medium. The containers were then placed into a shaker and rotated at $160 \mathrm{rpm}$ for $72 \mathrm{~h}$ at a temperature of $26^{\circ} \mathrm{C}$. After shaking, the bacterial broth was stored in sterile $50 \mathrm{~mL}$ tubes at $-18^{\circ} \mathrm{C}$ until required, at which point they were defrosted at room temperature for $5 \mathrm{~h}$.

Inoculation of SRS-media (SNS-PHP) and pea planting: In the experiments with pea, we only used the Sulphonated-Neutralized-Sytrene PolyHIPE Polymers (SNS-PHP) with pore size of $150 \mu \mathrm{m}$. They were in cubical form (ca. $125 \mathrm{~mm} 3$ ). Dry SNS-PHP samples, weighing 1 gram were soaked with $25 \mathrm{~mL}$ of bacterial broth dispersion. Air dried and sieved ( $2 \mathrm{~mm}$ size) horticultural soil $(150 \mathrm{~g})$ was mixed with $50 \mathrm{~g}$ horticultural sand and the resulting mixture of soil was mixed with $1 \mathrm{~g}$ SNS-PHP already soaked in $25 \mathrm{ml}$ of bacterial broth. This soil-PHP mixture was placed at the bottom of a plant pot and occupied a height of $25 \mathrm{~mm}$. The remaining bacterial broth (ca. $5 \mathrm{ml}$ ) from the adsorption of SNS-PHP was poured over the soil centrally where a single pea seed was placed. The seed was then covered with $700 \mathrm{~g}$ of the same soil (containing $0.251 \mathrm{sand} / \mathrm{l}$ soil). Total height of the soil in the pot was $75 \mathrm{~mm}$. As the top $50 \mathrm{~mm}$ soil did not contain any SNS-PHP, the overall concentration of SNS-PHP (SRS-media) in the pot was $0.11 \mathrm{~g}$ SRSmedia/g soil on dry basis. All pots were then given 50 $\mathrm{mL}$ water and were randomly distributed within a $2 \times 2$ $\mathrm{m}^{2}$ area of greenhouse. There was no water stress as the pots were watered daily.

After 42 days, the shoots were cut at the base and the pea pods were removed and kept separate from the rest of the stem and leaves. The yields of the pea pods were measured separately to the rest of the shoot biomass (stems and leaves), to allow for a comparison between crop yields as well as the total (i.e., stem and pods) biomass yields. The pea pods and stems from each pot were stored in sealable plastic bags and then immediately weighed to determine the fresh weight followed by the drying of the samples in an oven at $60^{\circ} \mathrm{C}$ for $72 \mathrm{~h}$ and then individually reweighed and recorded to determine the dry weight.

Root nodulation studies: The root association was further studied by placing a seed on a single inoculated SNS-PHP (ca. $35 \mathrm{~mm}$ in diameter after swelling in the presence of water) to act as a SRS-media. In the soil beneath the disc, the SNS-PHP was applied in the usual cube form so that the total SNS-PHP application was 5 $\mathrm{mg}$ polymer/g soil below the seed. A control treatment without Rhizobium was also used. The growth 
experiments in both cases were conducted for 42 days with daily watering.

Statistical analysis of plant yield data: Four replications were used for each treatment. The mean fresh and dry weights for each harvest were plotted into bar charts. The mean yields were compared using two sample t-tests of independence assuming equal variance at $95 \%$ confidence and confirmed using a one-way analysis of variance with a Tukey's Pairwise Comparison.

Scanning Electron Microscopy (SEM) of PolyHIPE Polymers: SEM equipped with Energy Dispersive Xray (EDX) analysis was used to measure the average pore and interconnect sizes using low magnification images. Two types of samples were fixed and examined under the SEM, the first being inoculated polymers used in the green house experiments and hence placed into the soil with the seeds and the second being polymers that had simply been autoclaved after sulphonation and then placed into an incubator with the bacterial broth. The latter was prepared so that a clean sample could be examined for growth of Rhizobium leguminosarum without potential contamination from native soil bacteria. It was prepared by soaking the polymer in the bacterial broth and leaving it in an incubator at $26^{\circ} \mathrm{C}$ for a period of 7 days. Both types of sample were washed and fixed using the same method, as described below.

Before fixing the $R$. leguminosarum inoculated within the polymer, the sample must be washed in a new container using Phosphate Buffered Saline (PBS). PBS was poured over the sample until it was completely immersed where it remained immersed in a sealed container for $10 \mathrm{~min}$, after which time the PBS was drained away. Next, the samples were soaked in $0.02 \mathrm{~g}$ Glutardialdehyde/g solution in sealed containers for $24 \mathrm{~h}$ at room temperature followed by a final wash in PBS for $10 \mathrm{~min}$ to remove any debris and complete the fixation process (Akay et al., 2005; Erhan et al., 2004).

The samples needed to be preserved until examined under the SEM and this was achieved via dehydrating using ethanol. Dehydration was achieved by first immersing the sample in $0.1 \mathrm{~g}$ ethanol/g aqueous solution for a period of $10 \mathrm{~min}$, followed by the drainage of ethanol and the re-immersion in $0.25 \mathrm{~g}$ ethanol/aqueous solution for a further $10 \mathrm{~min}$. The process was then repeated with $0.50,0.75 \mathrm{~g}$ ethanol/aqueous solution and then the sample was stored in pure ethanol at $4^{\circ} \mathrm{C}$. Before examination under SEM, the samples are critically point dried. The surfaces or fracture surfaces of the samples were examined under SEM after gold coating under vacuum. Pore size was measured by measuring the pore diameter on the SEM micrographs and number average size recorded after correcting them to take into account of the random fracture nature of the fracture surface (Akay et al., 2002; Galan and Valle, 2006).

Some of the PHP samples were used to cultivate bacteria and subsequently use them in soil for nitrogen fixation as well as for soil conditioning. In both cases plant roots penetrate into the sulphonated neutralised styrene (spongy) PHP and therefore the interactions between PHP+plant as well as between PHP + bacterium + plant could be studied by examining the fracture surface of the PHP. Due to the presence of the biological components within PHPs, a different SEM sample preparation technique was used. When investigating the samples containing plant roots and/or bacteria, biomaterial associated with PHP was first fixed and subsequently coated with carbon (for low magnifications with EDX analysis) or gold (for high magnifications) as described above.

Nutrient content analysis: Nutrient content analysis was carried out by Natural Resource Management Ltd, Bracknell, Berkshire, UK. Dried plant tissue samples were analysed for Nitrogen, Sulphur, Phosphorus, Potassium, Magnesium, Calcium, Manganese, Copper and Iron. Nitrogen and sulphur were analysed by a Dumas technique (combustion at ca. $1000^{\circ} \mathrm{C}$ in an oxygen atmosphere followed by catalytic conversion of the gases and subsequent analysis by chromatography with TC detection) on a modified Carlo Erba NA2500 Analyser. The instrument was calibrated using certified reference materials of similar matrix and known amounts of Nitrogen and Sulphur.

Phosphorus, Potassium, Magnesium, Calcium, Manganese, Copper and Iron were analysed by digesting samples in $50 \%$ nitric acid in a commercial laboratory microwave system (CEM Corp., Mars Xpress system). The extract was diluted and analysed by inductively coupled plasma-optical emission spectroscopy using a Perkin Elmer 5300DV instrument. The instrument was calibrated using commercial standard solutions traceable to international standards.

\section{RESULTS}

Characteristics of polymers used as SRS-media: Water adsorption capacity: The water uptake capacity and time taken to reach to this capacity for four types of polymers are shown in Table 1. If the sulphonatedneutralised styrene PolyHIPE Polymer (SNS-PHP) has small pore size, it is restraint from swelling upon contact with water and hence the water uptake capacity is dictated by the phase volume of SNS-PHP. The rate of adsorption and total absorption capacity are both low. These non-swelling SNS-PHPs are referred to as rigid-PHPs. In the case of large pore-size (D>50 $\mu \mathrm{m})$ SNS-PHPs, water uptake capacity was large because 
they swell when they adsorb water and became elastic as long as they are in contact with water. We refer to these SNS-PHPs as spongy PHPs. Elasticity of the nonsulphonated polymer can be introduced by using 2ethylhexyl acrylate co-monomer. But these polymers are hydrophobic and they are rendered hydrophilic by sulphonation (and subsequent neutralisation) and hence they can be used as soil additive. These polymers are denoted as SNS/EHA-PHP. However, if these polymers are washed to remove surfactant, their water adsorption capacity and water adsorption rate both become large very similar to that of spongy PHP as seen in Table 1. We refer to SNS/EHA-PHPs with large water adsorption capacity as elastic-PHP. We observed that the rigid SNS-PHPs do not allow root penetration and therefore they cannot be used to support bacteria for biologically active SRS-Media. Hence, we only use the spongy or elastic PHPs in our green house experiments.

Scanning Electron Microscopy (SEM) studies of SRS-media polymers: Figure 1a, b illustrate the typical micro-architecture of sulphonated, neutrilised crossed linked styrene PHPs at three magnification. Compared with the classical thermal sulphonation techniques (Wang and Holladay, 2005; Lens and Lens, 2005; Kucera and Jancar, 1998) the microwave sulphonation (Akay et al., 2010) is not only very fast but also highly effective in the enhancement of the surface area which provides a nano-porous wall structure for the transport of water, nutrients and metabolites for bacteria and plant roots within the SRS-media.

Table 1: Water adsorption characteristics of various sulphonatedneutralised PolyHIPE Polymers as a function of processing conditions

\begin{tabular}{|c|c|c|c|c|}
\hline $\begin{array}{l}\text { Type of } \\
\text { Sulphonated } \\
\text { PHP }\end{array}$ & $\begin{array}{l}\text { Preparation } \\
\text { for } \\
\text { sulphonation }\end{array}$ & $\begin{array}{l}\text { Water } \\
\text { absorption } \\
\text { capacity after } \\
1 \text { minute }(g / g)\end{array}$ & $\begin{array}{l}\text { Equilibrium } \\
\text { water } \\
\text { absorption } \\
\text { capacity }(\mathrm{g} / \mathrm{g})\end{array}$ & $\begin{array}{l}\text { Nominal } \\
\text { pore } \\
\text { size }(\mu \mathrm{m})\end{array}$ \\
\hline $\begin{array}{l}\text { Rigid crosslinked } \\
\text { sulphonated - } \\
\text { neutralized } \\
\text { styrene } \\
\text { homopolymer } \\
\text { (SNS-PHP) }\end{array}$ & $\begin{array}{l}\text { Washed and } \\
\text { dried before } \\
\text { acid adsorption }\end{array}$ & 8.3 & 8.4 & 20 \\
\hline $\begin{array}{l}\text { Spongy } \\
\text { Crosslinked } \\
\text { sulphonated- } \\
\text { neutralized } \\
\text { styrene } \\
\text { homopolymer } \\
\text { (SNS-PHP) } \\
\text { - Spongy PHP* }\end{array}$ & $\begin{array}{l}\text { Washed and } \\
\text { dried before } \\
\text { acid absorption }\end{array}$ & 18.1 & 18.1 & 150 \\
\hline $\begin{array}{l}\text { Elastic } \\
\text { Crosslinked } \\
\text { Sulphonated } \\
\text { - neutralized } \\
\text { styrene - 2- } \\
\text { ethylhexyl } \\
\text { acrylate copolymer } \\
\text { (SNS/EHA-PHP) }\end{array}$ & $\begin{array}{l}\text { Adsorption of } \\
\text { acid without } \\
\text { washing } \\
\text { acid adsorption }\end{array}$ & 12.3 & 12.5 & 90 \\
\hline $\begin{array}{l}\text { Elastic } \\
\text { crosslinked } \\
\text { sulphonated- } \\
\text { neutralized styrene- } \\
\text { 2-ethyl hexylacrylate } \\
\text { copolymer } \\
\text { (SNS/EHA-PHP) - } \\
\text { Elastic PHP* }\end{array}$ & $\begin{array}{l}\text { Washed and } \\
\text { dried before }\end{array}$ & 15.9 & 18.8 & 90 \\
\hline
\end{tabular}

*PHPs used in greenhouse experiments
These micrographs clearly illustrate the presence of hierarchic pore structure suitable for biological systems such as the SRS-media in which bacterial and root hair penetration is facilitated by large interconnecting holes and the pore walls adsorb water and nutrients.

\section{Grass root association with PHP:}

Scanning electron microscopy of bioactive PHP with bacteria and plant roots: Root association with spongy or elastic PolyHIPE Polymers (SNS-PHPs or SNS/EHAPHPs) starts as soon as the roots encounter the PHP particles in the soil. Our on-going research indicates that this encounter is bias as the roots appear to grow towards the SRS-media due to hydrotropism and chemotropism (Uso et al., 1998). This is particularly true when there is water stress. At the end of the growth period, following the final cutting of the grass, roots were recovered from the soil, washed and photographed (Fig. 2). The roots strongly penetrated the PHP structure so that they remained even after rinsing the soil away from the roots with water and lifting up the entire root network by just holding onto a few grass shoots. The roots were observed not only attach to the surface of the polymer, but actually grow through the structure so that it became an integral part of the root network.

This phenomenon was more closely examined under SEM (Fig. 3a-e by breaking the PHP+root constructs and examining the fracture surface. It was clear that not only root hairs but also the primary roots were travelling through the polymer. Figure $3 \mathrm{a}$ indicates the presence of primary roots (size ca. 200 $\mu \mathrm{m})$ and root hairs (size ca. $10 \mu \mathrm{m}$ ) within the SNSPHP although the interconnect size of PHP is much smaller than the diameter of the primary root. It appears that the growing root displaces the spongy/elastic polymer and travel through them as shown in Fig. 3b while Fig. 3c illustrates the cross-section of the primary root. In order to promote root-PHP interactions, some of the spongy PHPs had $2 \mathrm{~mm}$ diameter capillaries through them. These large capillaries appear to provide suitable environment for root branching within PHP as seen in Fig. 3d, e.

After growing grass for 42 days with daily watering, the resulting root-PHP association was investigated further using the elastic sulphonated-neutralisedstyrene/2-ethylhexyl acrylate PolyHIPE Polymer (SNS/EHA-PHP) (Fig. 4a, b). SEM studies showed that the grass roots were more ragged in the SNS/EHA-PHP (pore size $90 \mu \mathrm{m}$ ) compared with the spongy sulphonated-neutralised-styrene PolyHIPE Polymer (SNS-PHP, pore size $150 \mu \mathrm{m}$ ) as seen in Fig. 4a, b. 


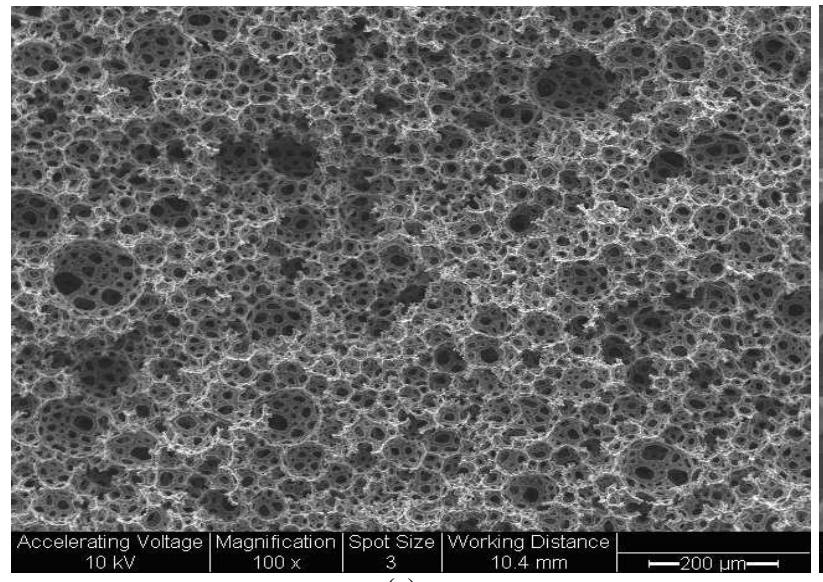

(a)

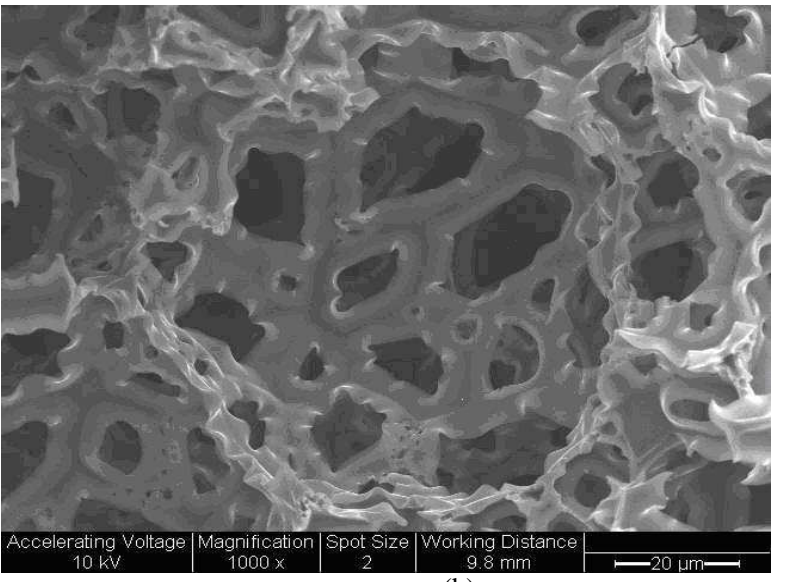

(b)

Fig. 1: (a) Low magnification SEM (b) High magnification SEM of sulphonated PHP used in the experiments

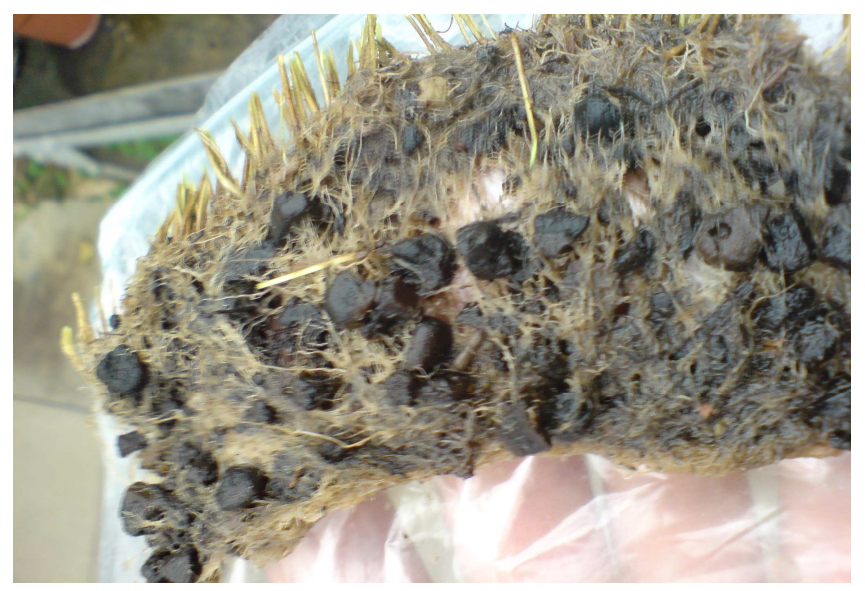

Fig. 2: Grass root association when $0.5 \%$ w/w ca. $125 \mathrm{~mm}^{3}$ sulphonated neutralised styrene (spongy) PolyHIPE Polymer (SNS-PHP) was used in the soil as soil conditioner with daily watering

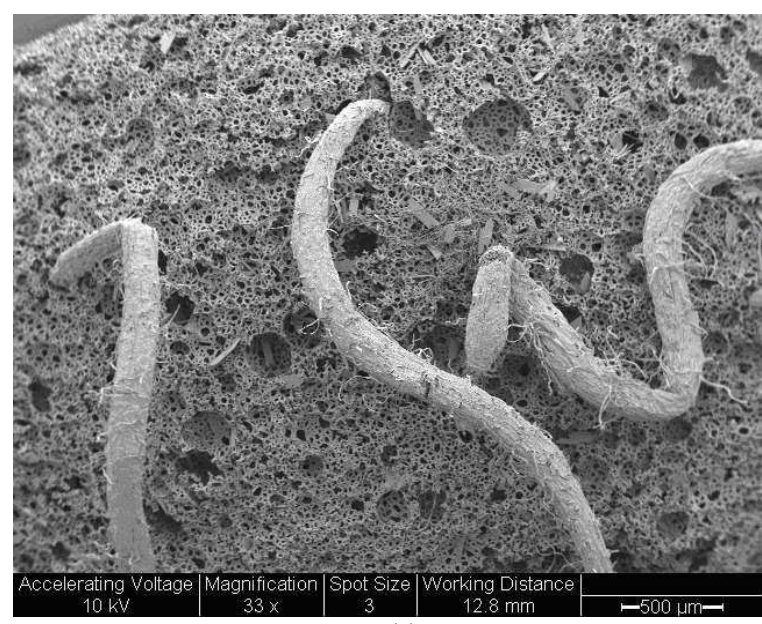

(a)

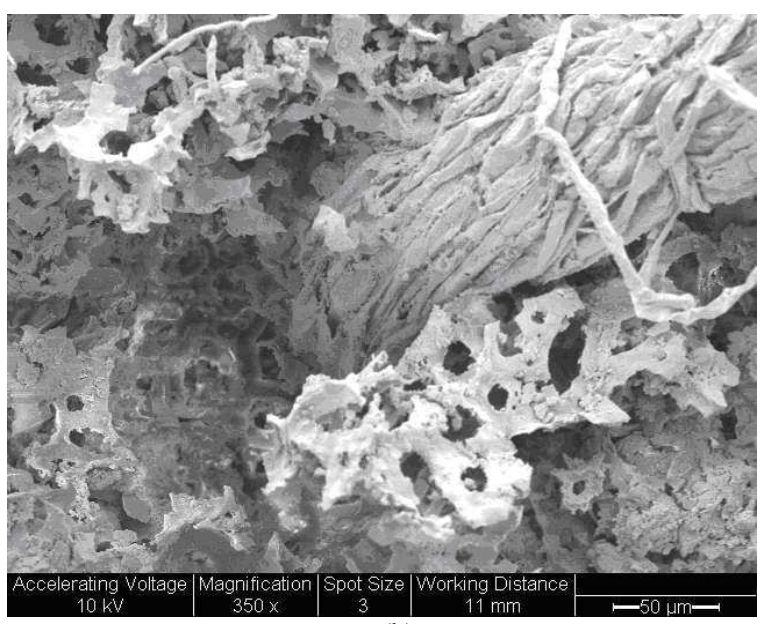

(b) 


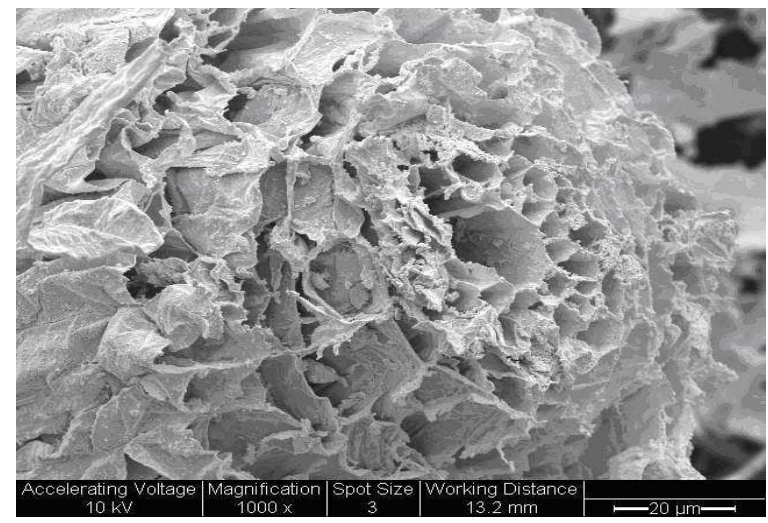

(c)

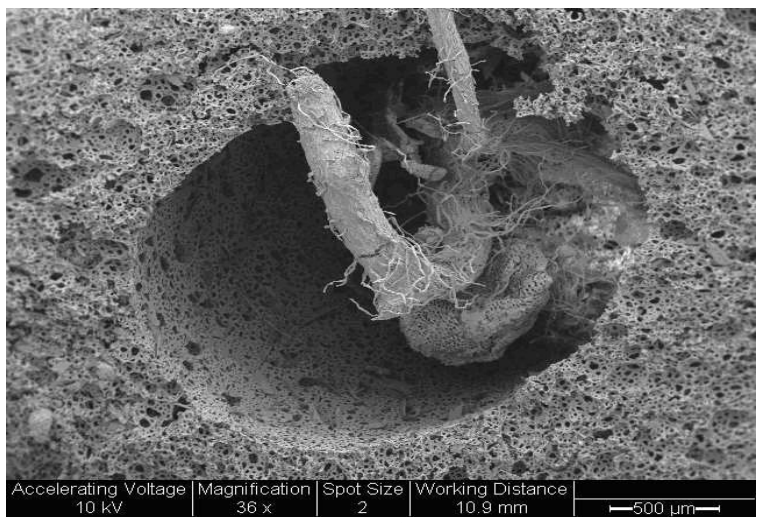

(d)

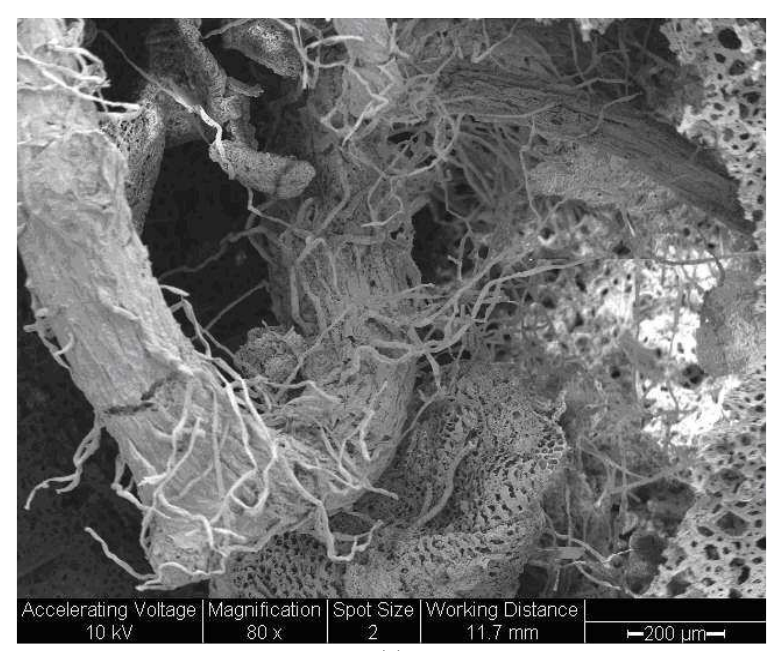

(e)

Fig. 3: SEM of the grass root association withsulphonated neutralised styrene (spongy) PHP (SNS-PHP) at different magnifications. (a): Presence of the primary grass roots growing through the SRS-media. (b): Same as in (a) at higher magnification. (c): Same as (b) at higher magnification. (d): Root growing within a $2 \mathrm{~mm}$ capillary in the SRS-media. (e): Same as in (d) showing the presence of root hairs.

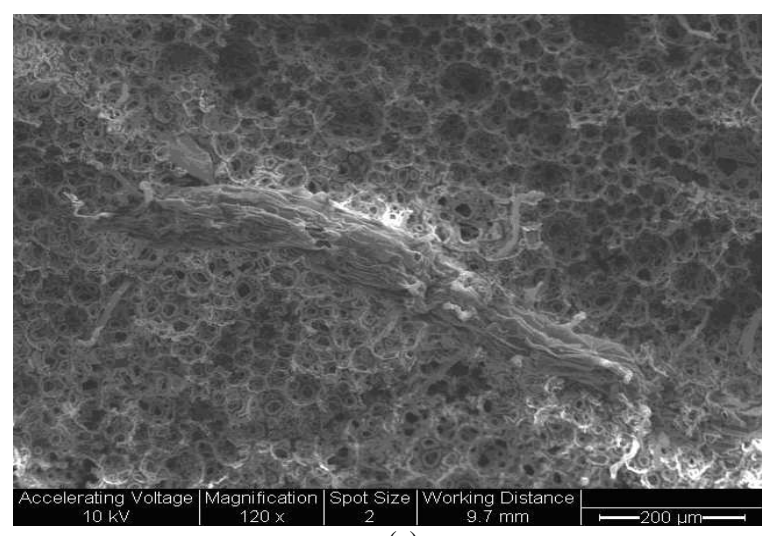

(a)

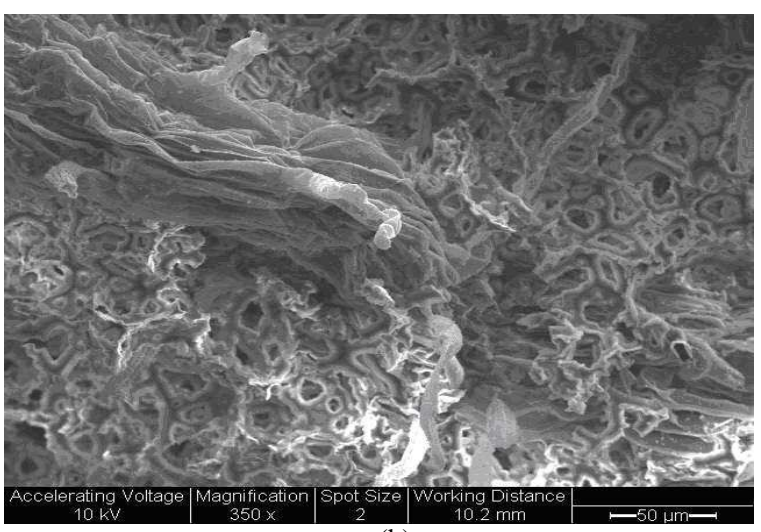

(b)

Fig. 4: SEM of root growing in sulphonated neutralized styrene elastic PolyHIPE Polymer (SNS/EHA PHP). (a) Low magnification SEM (b): High magnification SEM 


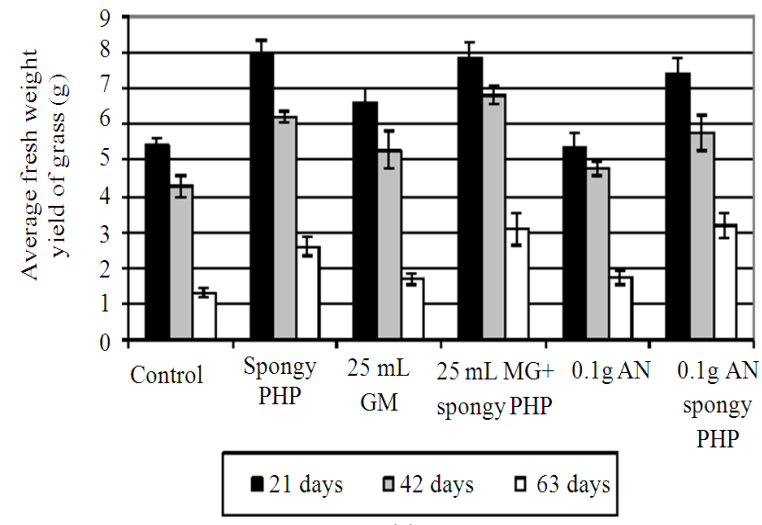

(a)

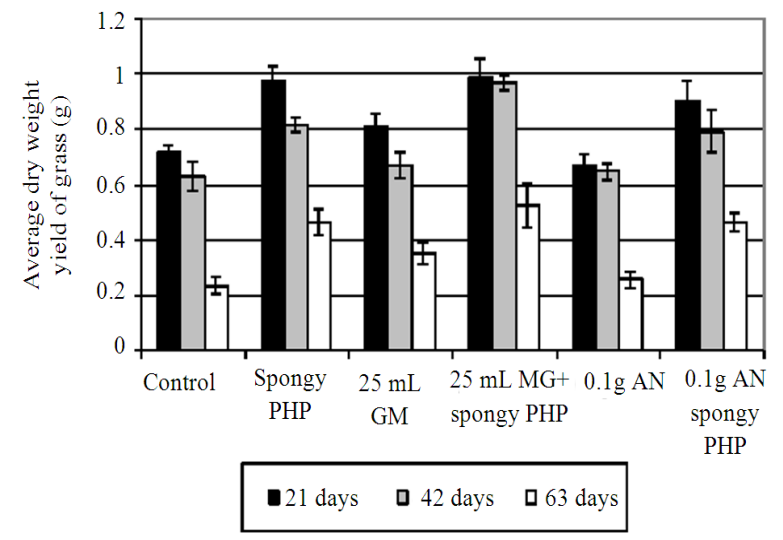

(b)

Fig. 5: Effect of fertiliser treatment on biomass yield of grass grown with or without sulphonated nutralised styrene (spongy) PolyHIPE Polymer, SNS-PHP. (a) Fresh yield (b): Dry yield

SRS-media for fertiliser conservation and slow release for grass: Using Nitram ammonium nitrate (AN) as well as Miracle-Gro ${ }^{\circledR}(\mathrm{MG})$, it was possible to investigate whether sulphonated neutralised styrene (spongy) PolyHIPE Polymer (SNS-PHP) with $150 \mu \mathrm{m}$ pore size in cubical form could be used as slow release media for fertilisers in order to enhance grass yield.

Each slow release fertiliser treatment used was compared against a control without polymer or nutrients, as well as an equal fertiliser treatment in the soil without polymer. When fertilisers were adsorbed by SNS-PHP through a $25 \mathrm{~mL}$ solution, any excess water not adsorbed was evaporated in the air before the polymers were mixed with soil. This evaluation was conducted over an extended period (63 days) involving 3 harvests each after 21 days. Daily watering was employed. In these experiments there were 6 sets:

Set-1: (Control): No fertiliser or SNS-PHP were present in the soil.

Set-2: $\quad$ Soil contained $5 \mathrm{mg}$ SNS-PHP/g soil but no fertiliser.

Set-3: $\quad$ Soil contained 25mL Miracle-Gro (MG) per pot dispersed into the soil.

Set-4: Soil contained $5 \mathrm{mg}$ SNS-PHP/g soil containing $25 \mathrm{~mL}$ Miracle-Gro (MG).

Set-5: Soil contained 0.1g Nitram (Ammonium nitrate, AN) applied through a $25 \mathrm{~mL}$ solution per pot dispersed into the soil.

Set-6: Soil contained $5 \mathrm{mg}$ SNS-PHP/g soil which had $0.1 \mathrm{~g}$ Nitram (Ammonium nitrate, AN) applied through $25 \mathrm{~mL}$ solution per pot and dispersed into the soil.

First harvest yields: After 21 days, the fresh weight yields of grass (Fig. 5a) showed that all treatments, with the exception of $0.1 \mathrm{~g} \mathrm{AN}$, significantly enhanced $(p<0.05)$ the growth of grass. There was no statistical difference observed between the standard polymer treatment without fertiliser and those loaded with fertiliser. The lack of benefit from use of AN-fertiliser despite MG-fertilizer increasing yield, implies that the nitrogen in the fresh soil is not limiting and the MGfertilizer is benefiting the grass in terms of other nutrients supplied. The use of SNS-PHP containing MG-fertilizer did not significantly increase the yield compared to when MG was applied alone. However, SNS-PHP loaded with AN-fertilizer did produce a significant $(p<0.05)$ yield increase compared to the application of AN-fertilizer alone, as the latter had failed to have an effect compared to the control.

For the dry yields of the first harvest (Fig. 5b), only the polymer treatments produced growth significantly different $(p<0.05)$ from the control. None of the polymer treatments were significantly different from each other. Once more, SNS-PHP loaded with ANfertilizer did produce a significant yield increase compared to the application of AN-fertilizer alone.

Second harvest yields: For the second harvests (42 days) the applications of fertiliser alone, including the use of MG-fertilizer, was unable to improve the fresh weight compared to the control (Fig. 5a). The combined treatment of $25 \mathrm{~mL}$ MG-fertilizer with SNS-PHP produced the greatest mean yield $(6.81 \mathrm{~g} / \mathrm{pot})$ which was a $59.9 \%$ increase compared to the $4.26 \mathrm{~g} / \mathrm{pot}$ yield for the control. However, the combined treatment of $25 \mathrm{ml}$ MG-fertilizer with SNS-PHP did not produce a significantly different mean yield compared to the other SNS-PHP based treatments.

The dry weights (Fig. 5b) of the second harvest followed the trend of the fresh weight, but in this case the SNS-PHP containing MG-fertilizer had significantly higher yields than the control, $25 \mathrm{~mL}$ MG- 
fertilizer application and also the non-fertiliser containing SNS-PHP. The mean yield achieved with the combined treatment was $0.97 \mathrm{~g} / \mathrm{pot}$, a $54 \%$ increase on the $0.63 \mathrm{~g} /$ pot mean yield obtained by the control and a $44.8 \%$ increase on the $0.67 \mathrm{~g} / \mathrm{pot}$ average yield achieved from the direct application of $25 \mathrm{~mL}$ MG-fertilizer. This data confirms that the yield increase is not because of either the soil conditioning characteristics or the fertiliser itself, but because the SNS-PHP containing MG-fertilizer has successfully worked as a slow release fertiliser while fertilizer in soil started to deplete. We can conclude from the above results that without the soil additive SNS-PHP in the soil, fertilizer wash out is more severe whereas the polymers are able to adsorb both water and fertilizer and release them directly to the roots of the plant.

Third harvest yields: For the third harvest (63 days), all fresh weight yields decreased drastically and the effects of the fertiliser treatments were no longer significantly different to the control and the nonfertiliser containing SNS-PHP (Fig. 5a). The combined MG-fertilizer and polymer treatment was able to increase the fresh yield from 1.71-3.08 g/pot $(80.1 \%$ increases) and the dry yield from 0.35-0.52 g/pot (48.6\% increase) compared to direct application of MGfertilizer. As with the second harvest trials with $\mathrm{AN}$, it is only at the third fresh weight harvest that the $0.1 \mathrm{~g}$ AN-fertilizer began to increase yield compared to the control; however in this case, unlike earlier trials, the increase was not significantly different. The same is observed with the dry weight yields (Fig. 5b), with none of the fertiliser treatments significantly benefiting the yield, except when SNS-PHP was used.

Greenhouse experiments with pea plants using rhizobium inoculated SRS-media: Pea was used as a model legume crop so that the biomass and crop enhancement by the biologically active SNS-PHP could be tested. In these experiments there were 4 sets:

Set-1: (Control): This set contained no PHP or no additional bacteria or nutrient associated with the bacterial broth

Set-2: Each pot contained 1g SNS-PHP mixed with $200 \mathrm{~g}$ soil and placed at the bottom of the pot below the seed. No bacteria or broth added

Set-3: There is no SNS-PHP. Bottom $200 \mathrm{~g}$ soil contained $25 \mathrm{~mL}$ of bacterial broth

Set-4: Bottom $200 \mathrm{~g}$ soil containing 1g SNS-PHP soaked in $25 \mathrm{~mL}$ of bacterial broth

Total soil content of the pots was $900 \mathrm{~g}$ in all cases and hence the SRS-media was present at $1.1 \mathrm{mg}$ polymer/gram soil. These trials were conducted to compare the effects of both the soil conditioner and the bacterial broth on the yields of pea plants. The yields of the pea pods were measured separately to the rest of the shoot biomass (stems and leaves), to allow for a comparison between crop yields as well as the total (i.e., stem and pods) biomass yields.

Although the soil contains bacteria and nutrients (including nitrogen), during 41 days of growth, nutrients will deplete through washing and utilization by the plant. Hence, without nutrient depletion we do not expect to see any significant effect of Rhizobium inoculated SNS-PHP on biomass and crop yields. This conclusion is in line with the results obtained from soybean experiments when the soil nutrients were partially depleted in order to enhance the effect of SNSPHP (Uso et al., 1998).

Total yields of pea pod crop: Because of the large variation observed in the control yields, the two sample t-tests of independence assuming equal variance at $95 \%$ confidence showed that none of the treatments were actually able to significantly increase the fresh yield compared to the control (Fig. 6). However, the mean yield of the combined Rhizobium and spongy SNSPHP treatment was significantly different to the applications of just Rhizobium leguminosarum (55.2\% increase from $4.24 \mathrm{~g} / \mathrm{pot}$ ) and just spongy SNS-PHP (28.8\% increase from $5.11 \mathrm{~g} / \mathrm{pot}$ ).

For the dry weight yields of the pea crop (Fig. 6), the combined Rhizobium and spongy SNS-PHP treatment was able to significantly enhance the yields compared to all treatments, including the control. This combined treatment actually increased the average yield to $1.15 \mathrm{~g} / \mathrm{pot}$ compared to $0.68 \mathrm{~g} / \mathrm{pot}$ for the control (69.1\% increase) and $0.75 \mathrm{~g} / \mathrm{pot}$ compared to the direct application of Rhizobium (52.7\% increase). Hence, despite the large variation in control fresh weight yields, dry weight yields did confirm that the combined treatment (SNS-PHP + Rhizobium) was most beneficial to the growth of pea pods.

Although the combined Rhizobium and SRSMedia treatment did significantly increase dry yield, the use of broth inoculant alone had no effect on either the fresh or dry weight yields. This indicates that when applied directly to the soil, the bacterial broth was an unsuitable inoculant. Reasons for this might be that the concentration of the bacteria within the broth was not high enough to efficiently colonise the soil to ensure contact with the roots. It was also possible that the bacteria were unable to attach to soil particles when within a broth and hence were washed away upon watering. The use of SNS-PHP had overcome these problems by acting as a support matrix to encourage the growth of $R$. leguminosarum. The polymer not only provided a moisture store within the soil, but also acted 
as a support matrix for the bacteria, allowing them to grow in a more protective and desirable environment as well as encouraging interaction with plant root systems as indeed shown for bacteria (Akay et al., 2005; Erhan et al., 2004) and mammalian cells (Akay et al., 2002; Bokhari et al., 2003; Akay et al., 2004; Galan and Valle, 2006; Bokhari et al., 2005; Brebbia et al., 2011).

Shoot biomass yields: The shoot biomass yields (i.e., shoot and peas) were also measured and recorded. The fresh weight yields (Fig. 6) again showed that there were no significant differences in yield between the control and each of the other treatments. However, the combined Rhizobium and SMS-media treatment did result in a significantly enhanced yield from 7.77 to $12.8 \mathrm{~g} / \mathrm{pot}(64.4 \%$ increase) compared to the plain Rhizobium treatment.

For the dry weight yields (Fig. 6), one treatment did produce a significantly different yield to the control and that was the combined Rhizobium and SRS-Media treatment. The combined treatment again resulted in a significantly different yield increase from 1.29-2.08g/pot (61.2\% increase) compared to the plain Rhizobium treatment. However, unlike the yields for the pea pods, the combined treatment was not significantly different to that observed with just SRS-media was applied. It is also possible that the SNS-PHP + Rhizobium constructs when associated with the root system enhance crop yield at the expense of overall biomass.

The only significant yield enhancement is achieved when SNS-PHP was used as SRS-Media with Rhizobium. The average enhancement of dry pea crop yield was $69.6 \%$ while that of the dry biomass was $31.0 \%$ this is because enhancement of bacterial infection and nodulation as no water stress was present.

Root associations with SRS-media and root infection: To determine if $R$. leguminosarum was capable of growing within the pores of spongy SNSPHP, the bacterial broth was soaked into the pores of autoclaved samples of SNS-PHP and then washed and fixed for examination under SEM. Cross section analysis of the spongy SNS-PHP samples (Fig. 7) shows the presence of scattered bacteria as well as bacterial colonies with extra-cellular matrix and microscopic debris from the inoculant broth, throughout the polymer structure after 7 days incubation. In the soil, the polymer provides a relatively stress free environment compared to the soil alone and allows the bacteria to proliferate and avoid being displaced by water movement or other microorganisms. Nevertheless, we did not optimise the pore structure to enhance bacterial proliferation.

The PolyHIPE Polymer also attracted the roots as they move through the soil. The roots actually penetrate through the structure of the SNS-PHP, which becomes entwined within the entire root system of the pea plant as shown in Fig. 8 (a, b, c). Figure 8a illustrates the overall root-polymer association while Fig. $8 \mathrm{~b}$ shows a single root emerging from the SNS-PHP. Figure 8c shows the presence of a pea root within the spongy SNS-PHP observed when the fracture surface of the polymer was examined. It shows the distortion of the pores near the root and root hairs penetrating into the pores. This behavior was also observed when using the SNS-PHP as a soil conditioner for growing grass.

Tissue analysis of pea crop and shoots: As shown in Table 2, the use of SRS-media PHP with or without being inoculated with Rhziobium also increased the nitrogen and phosphorous content of the pea crop compared with the control (no polymer and no additional bacterium).

This increase was also marked when the equivalent amount of bacterium was placed in the soil instead of within the spongy polymer. Since nitrogen and phosphorous are the important components of the proteins, it also implies that the protein content of the pea crop is also enhanced when polymers are used.

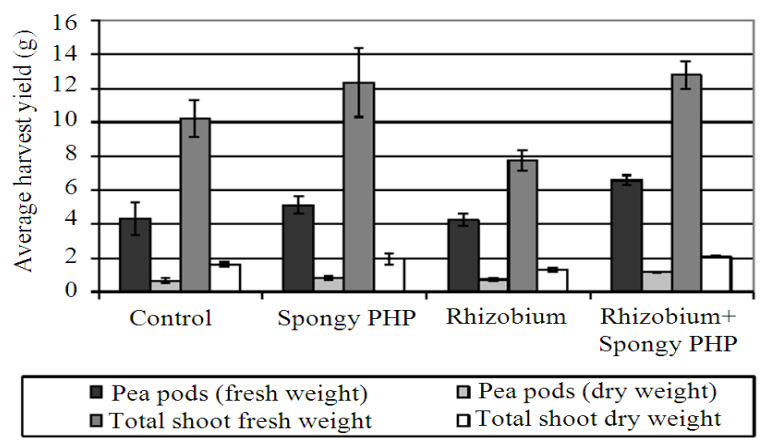

Fig. 6: Effect of inoculation treatment on the pea pod and total shoot yields after 41 days with or without spongy SNS-PHP

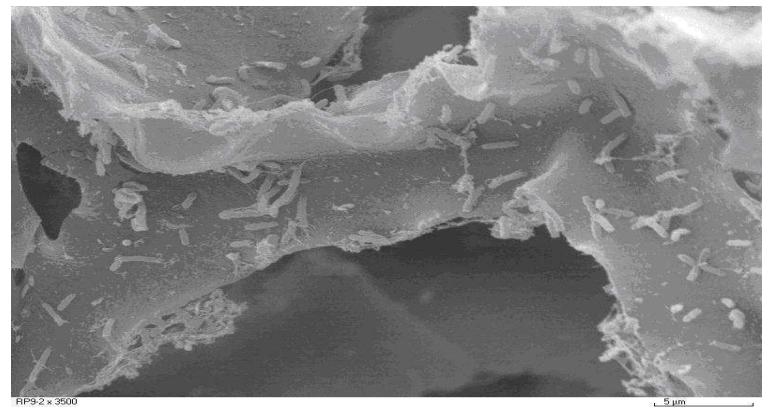

Fig. 7: Rhizobium leguminosarum growing on PolyHIPE after 7 days of incubation before the PolyHIPE Polymer (SNS-PHP) and bacterial constructs were placed in soil 
Am. J. Agri. \& Biol. Sci., 7 (2): 150-172, 2012

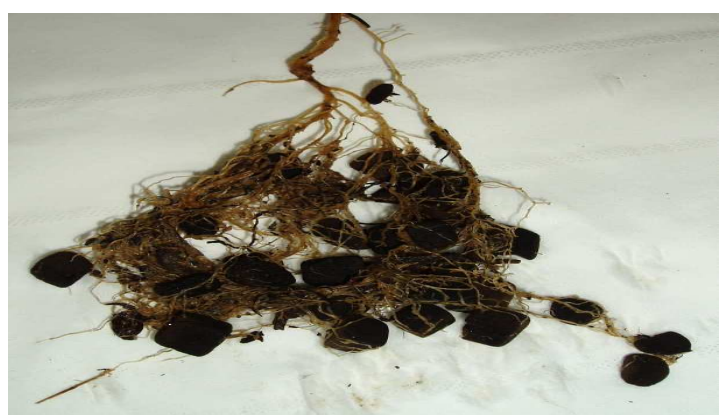

(a)

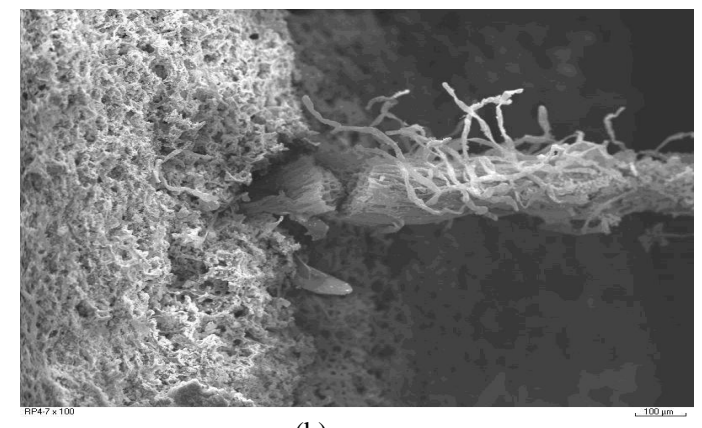

(b)

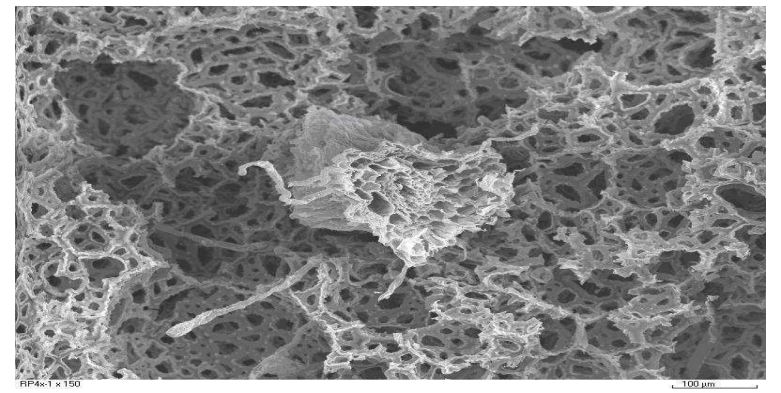

(c)

Fig. 8: Association of pea root with sulphonated neutralized styrene (spongy) PolyHIPE Polymer (SNS-PHP). Photograph of SNS-PHP association with pea roots (b): Pea root emerging from SNS-PHP (Magnification $\mathrm{x} 100)(\mathrm{c})$ : Pea root emerging from SNS-PHP surface (Magnification $\times 150$ )

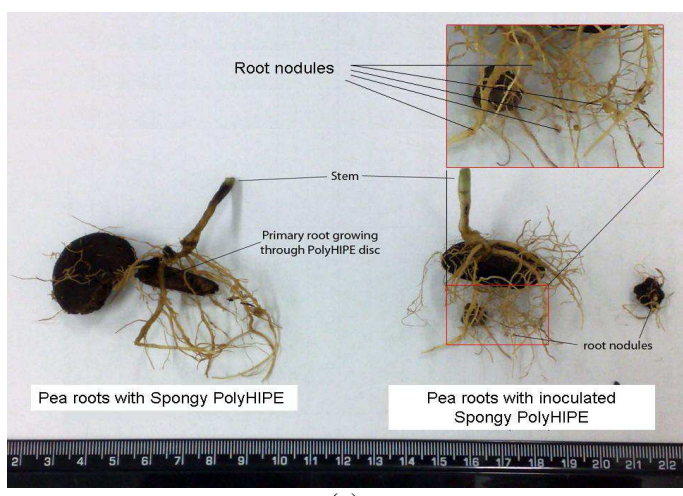

(a)

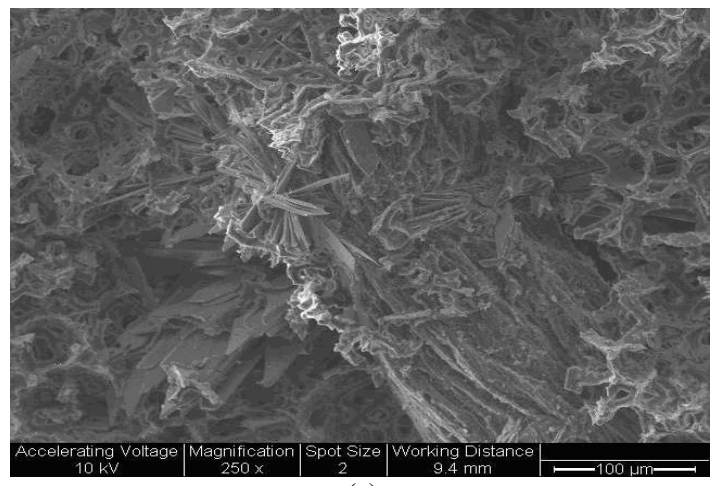

(c)

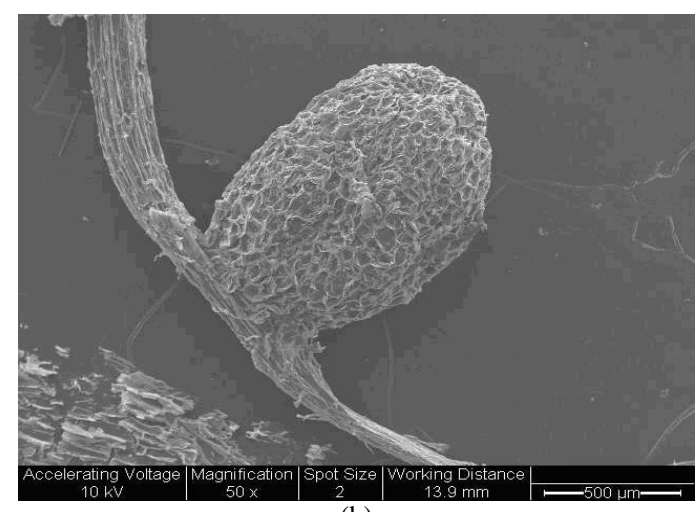

(b)

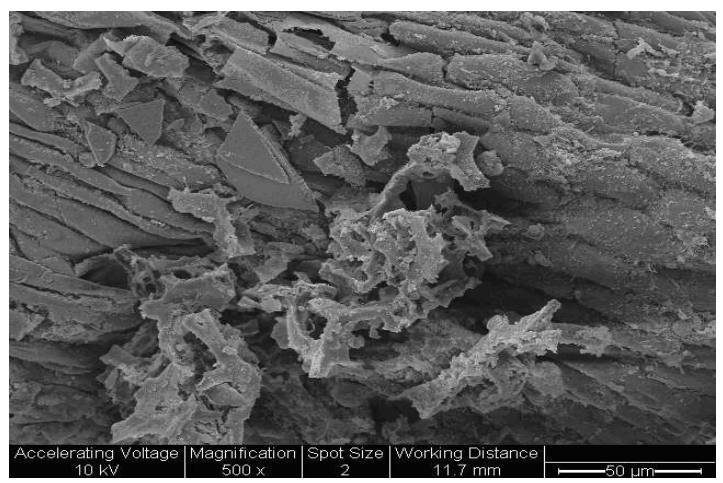

(d) 


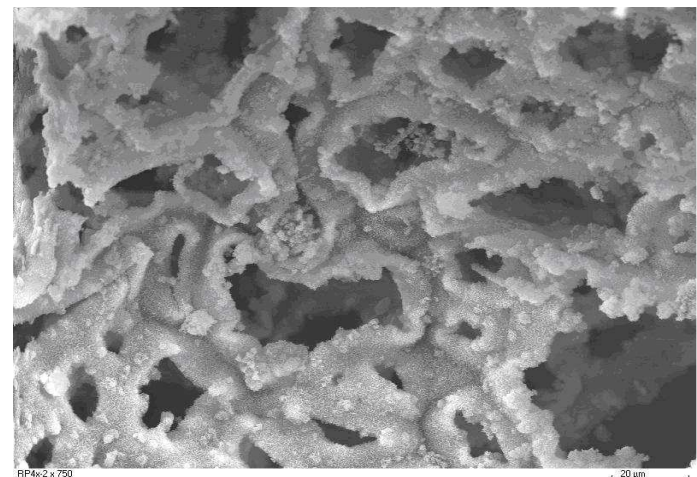

(e)

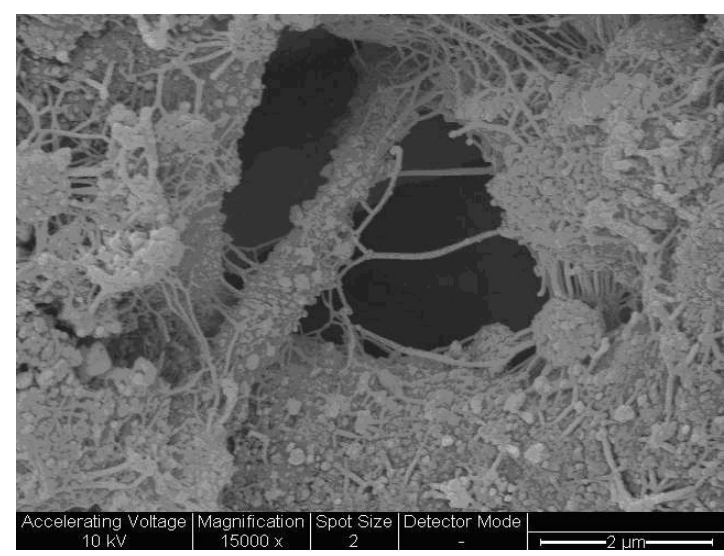

(g)

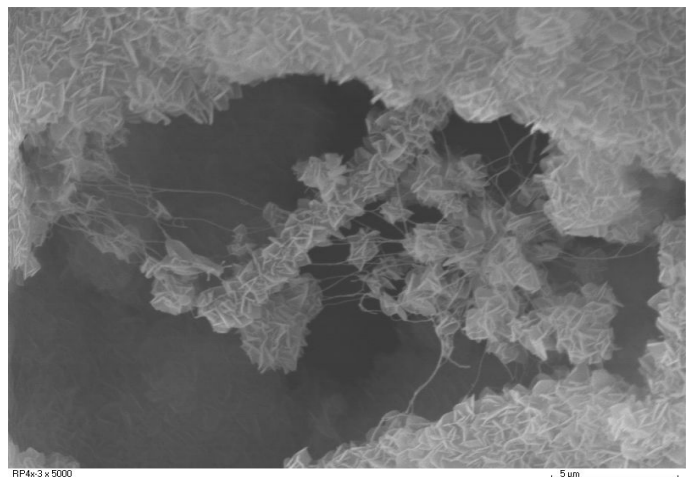

(f)

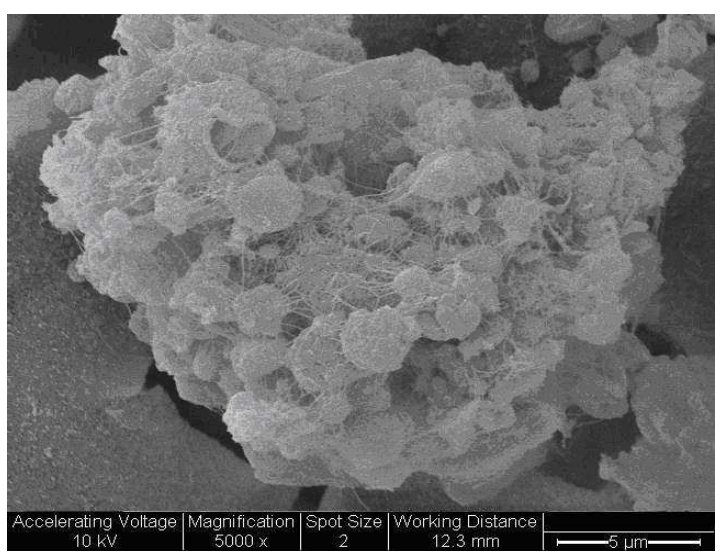

(h)

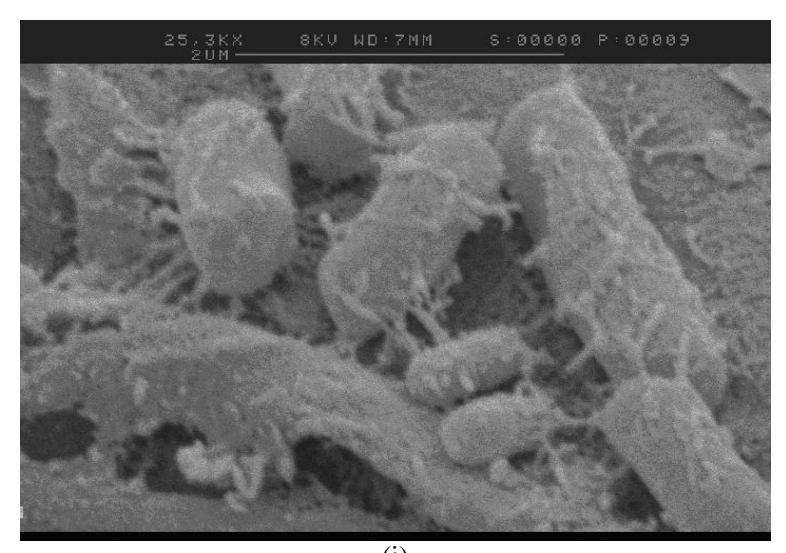

(i)

Fig. 9: Images of pea root association with sulphonated neutralized styrene PolyHIPE Polymer(SNS-PHP) inoculated with Rhizobium showing the root-bacterium association. (a) Photographs of pea plant roots associated with SNS-PHP (used just under the seed in the form of a disk) showing that the roots after emerging from the SNS-PHP are nodulated whereas the others are not nodulated. (b) SEM of the pea root nodule formed after being infected with the bacteria within SNS-PHP. (c) SEM of pea root within SNS-PHP showing the presence of debris and SNS-PHP structure. (d) Pea root growing through the SNS-PHP and creating debris. (e) Distortion of the SNS-PHP structure and interconnects due to the root growth and the presence of root exudates. (f) Creation of a microenvironment containing roots, bacteria and SNS- PHP. (g) Bacterial colonies within the SNS-PHP micro-environment. (h) Detail of a large bacterial colony grown in SNS-PHP. (i) Detail of bacteria growing in SNS-PHP 


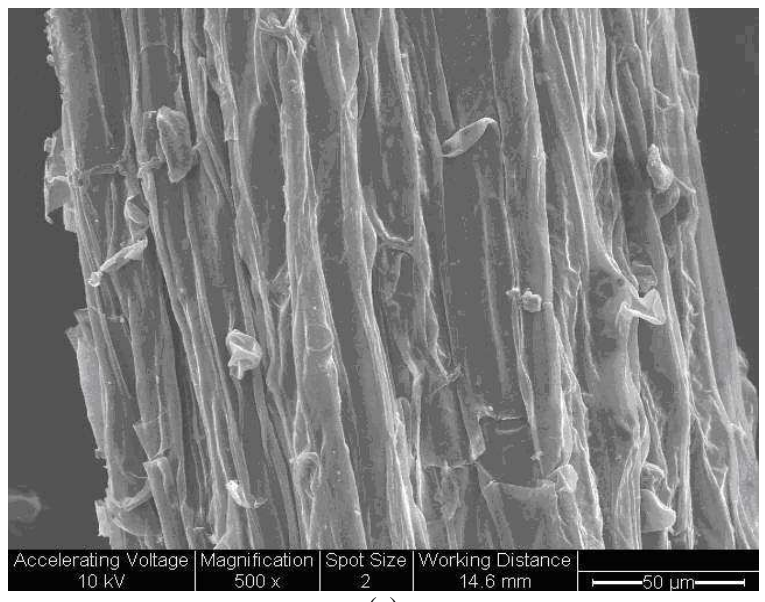

(a)

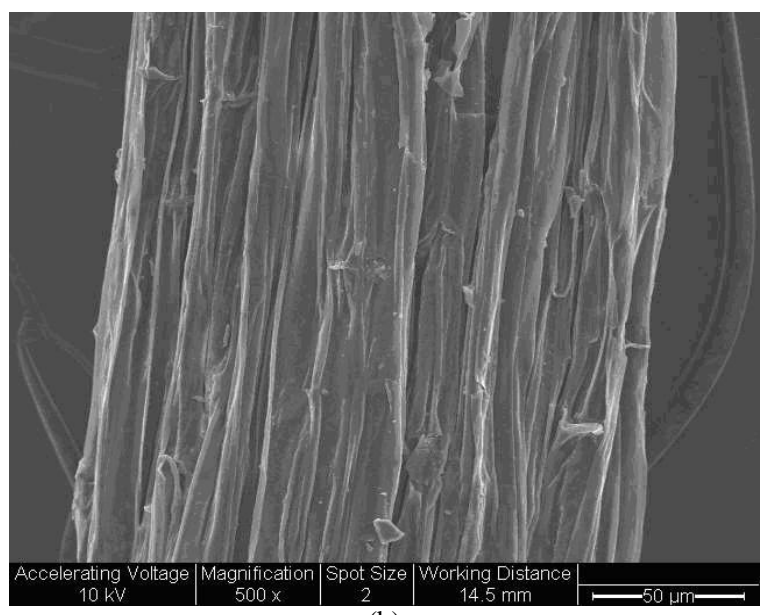

(b)

Fig. 10: The effect of root and SNS-PHP interaction on the fibrous structure of the pea root. (a) Fibrous root tructure after passing through the SNS-PHP. (b) Fibrous root structure when the root is solely grown in soil

Table 2:Tissue analysis of plant (shoot and pea) for different treatments compared with the control: Percent difference in nutrient/metal content compared to the control when soil contains no SNS-PHP and no additional Rhziobium

\begin{tabular}{|c|c|c|c|c|c|c|}
\hline \multirow{2}{*}{$\begin{array}{l}\text { Property } \\
\text { Element }\end{array}$} & \multirow{2}{*}{$\begin{array}{l}\begin{array}{l}\text { SNS-PHP only } \\
\text { (No Rhizobium) }\end{array} \\
\text { Shoot \% }\end{array}$} & \multicolumn{2}{|c|}{ Control + Rhizobium } & \multicolumn{3}{|c|}{ SNS-PHP + Rhizobium } \\
\hline & & Pea $(\%)$ & Shoot (\%) & Pea (\%) & Shoot (\%) & Pea $(\%)$ \\
\hline Nitrogen & 9.63 & 20.11 & -45.85 & 7.06 & -11.59 & 65.49 \\
\hline Phosphorus & 15.01 & 16.96 & -41.07 & 28.85 & 5.61 & 90.18 \\
\hline Potassium & 21.87 & 11.80 & -36.44 & 19.93 & 15.84 & 81.15 \\
\hline Magnesium & 26.63 & 22.67 & -20.16 & 10.81 & 25.53 & 78.11 \\
\hline Calcium & 14.37 & 24.55 & -21.12 & 9.11 & 26.95 & 88.72 \\
\hline Sulphur & -17.36 & 9.75 & 13.51 & 28.31 & 13.19 & 70.37 \\
\hline Manganese & 44.01 & 15.85 & -20.58 & 4.66 & -10.95 & 7.74 \\
\hline Copper & 35.93 & -10.83 & -33.11 & 17.95 & 10.71 & 25.87 \\
\hline Iron & 156.23 & 81.44 & 403.78 & 106.05 & 34.35 & 54.03 \\
\hline
\end{tabular}

It was also observed that the metal content of the pea as well as that of the shoots in most cases were also enhanced compared with the control. These enhancements were due to the fact that the spongy SNS-PHP acts as an ion exchange media and cations were absorbed by the polymer and subsequently taken up by the plant.

SRS-media/pea root interactions and root nodulation: Due to its potential as novel delivery system, the SRS-media/root association was further studied. By placing a seed on a single inoculated SNS-PHP and allowing the plant to grow. When the spongy SNS-PHP discs were inoculated using bacterial broth and subsequently used in the soil, the bacteria were able to grow within the porous matrix whilst the seeds germinated.

As the roots reach and penetrate through the polymer structure, they come into contact with large numbers of bacteria within confined environment which enhances bacterial/root association leading to root nodule formation as shown in Fig. 9a. One could visually observe that only the roots which passed through the inoculated SNS-PHP formed nodules. If there was no inoculation, roots still penetrated into the biologically inactive SNS-PHP (also shown in Fig. 9a) but upon emerging from the SNS-PHP, they did not form nodules. Figure $9 \mathrm{~b}$ illustrates the nodule formation after the root emerges from the SNS-PHP. Figure 9c and d show the inner structure of the SNS-PHP at two different magnifications with roots growing through it and creating a large number of debris. A closer investigation of the fracture surfaces of the SNS-PHP showed (in Fig. 9e and $f$ that the pore surface of SNSPHP) were covered with what appeared to be root exudates (Neumann and Romheld, 2000; Hatfield, 2005; Carvalhais et al., 2011).

They were not present without bacterial inoculation. As seen in Fig. 9g-i, a microenvironment was created within the pores which appeared to have root hairs, bacteria and debris. Hence, we can conclude that the microscopic environment in the pores is responsible for the observed crop yield enhancement when the SRS-media was biologically active. We also observe that the pea roots which grow through the SRSmedia have more rugged structure (Fig. 10a) compared with the roots which grow without any interaction with the SRS-media as seen in Fig. 10b.

\section{DISCUSSION}

Nature's processing technology and process intensification: Recently, Process Intensification through the mimicking of the human body has been demonstrated in chemical technology using novel composite nano-structured micro-porous materials 
(Brebbia et al., 2011; Akay, 2011; Wang and Holladay, 2005; Galan and Valle, 2006; Akay and Vickers, 2010), tissue engineering (Akay et al., 2002; Bokhari et al., 2003; Akay et al., 2004; Galan and Valle, 2006; Brebbia et al., 2011) and biotechnology (Akay et al., 2005) which also revealed the existence of the 'confinement phenomenon' in surface science and biology (McKetta, 1995). The important elements of the human body's processing strategy can be summarised as:

- High surface area-to-volume ratio for heat and mass transfer (i.e., high TAD in the range of $10 \mathrm{k}-$ $100 \mathrm{k} \mathrm{m}^{2} / \mathrm{m}^{3}$ )

- Hierarchical length scale for accessibility, continuous process and maintenance

- Mass transfer and communication across nano-size barriers (bilayers)

- Monolithic unit operations with continuous product removal

- Physiological stress dependent response in 3D cell culture with its own cell-support system which leads to the 'confinement phenomenon

The micro-architecture of cells in 3D-culture provides cell-cell communication for collective function as complete cell autonomy results in tissue specificity. Isolated cells lose most functional differentiation when separated and placed in traditional cell cultures. There is now a growing opinion that cell function is regulated by microenvironment and tissue architecture (Bissel et al., 2003). The effect of microenvironment in bacteria is evaluated in terms of environmental stress as well as in terms of alteration of the metabolic pathway and it is suggested that the physiological stress should be controlled in order to control the metabolic activity, viability, differentiation, productivity and gene expression patterns.

Nature's processing in photosynthesis through plants involves two domains; plant leaves and plant roots. Although the synthesis involving leaves and roots can also be deemed to be highly efficient, the accessibility to conversion energy (solar energy) by the leaves and to nutrients, water and catalysts (soil microorganisms) are on the other hand inefficient since TAD in both cases is very small and in the case of plant root system, to some extent, it is also random, although the recent research in hydrotropism and chemotropism suggests that there are driving forces generated by the plant roots for selectivity. Any randomness emanates from the fact that soil is the carrier medium for water, nutrients and microorganisms and therefore has several other complex function to maintain biodiversity. Although there are inherent mechanisms to promote root interactions with microorganisms/nutrients/water, these mechanisms are not efficient due antagonistic interactions between water/nutrients/ microorganisms; as uncontrolled water supply results in the depletion of nutrients and microorganisms from the rhizosphere where the multiple interactions take place. Furthermore, due to the presence of other microorganisms, even when single useful bacterium cultures are reintroduced into soil at very high population levels, it is immediately subjected to competitive and antagonistic effects from the indigenous microflora, causing population decline (Bashan, 1998).

In plants, rhizosphere can be considered to be a bioreactor in which the functional components include water, nutrients, bacteria and roots. Here too, the release of root exudates is affected by the plant physiological status (Neumann and Romheld, 2000; Hatfield, 2005; Carvalhais et al., 2011). Hence the process intensification strategy used in bioprocesses can be applied to the enhancement of rhizosphere efficiency to achieve AgroProcess Intensification through the introduction of synthetic rhizosphere media in the soil to enhance TAD and promote the interactions between water, nutrients, bacteria and plant roots. This can result in the creation of engineered ecosystems for AgroProcess Intensification (Akay and Burke, 2010; Burke et al., 2010).

\section{Potential uses of synthetic rhizosphere media:} Enhancement of root/water/nutrient/bacterium interactions: In order to achieve selective root/water/nutrient/microorganism interactions without any antagonistic effects while protecting useful soil bacteria, conserving water and nutrients, we used the SRS-media. However, in order to ensure that the plant roots selectively seek and associate with SRS-media, several restrictions are placed on the type of material used as SRS-media; they include high water adsorption rate and capacity, elasticity, pore size, nano-porosity of the pore walls, ability to act as an efficient support for bacteria so as to utilise the 'confinement phenomenon' to achieve BioProcess Intensification. AgroProcess Intensification through the application of PIM principles is only possible if the root growth selectively targets the SRS-media and root hairs and primary roots extensively form a network through and around it. The observed extensive root association clearly indicates that the roots are directed towards the source of water and nutrients as expected from hydrotropism and chemotropism. It is these properties of the plant roots that allow extensive root and SRS-media association and makes the root association process selective rather than random.

The multiple interactions within the SRS-media resulted in process intensification through the same 
mechanism as that observed in process intensification and miniaturization in chemical and biological processes in which the mass transfer was enhanced by the reduction in diffusion path, accessibility of catalytic sites, enhancement of TAD and in biological systems 3dimensional culture and quorum signalling. In addition, 'side reactions' (i.e., water and nutrient wastage) were inhibited, catalyst concentration and activity were maintained through the protection of useful bacteria and root exudates in the pores. Roots growing out of the SRSMedia were already infected with bacteria and needs no further infection with soil bacteria. In fact, the effect of the SRS-media on nodulation was clearly observable in plant roots if they pass through the SRS-media and there were hardly any present if the root had not grown through the SRS-media containing bacteria. These SRS-media characteristics can also be used to deliver other active agrochemicals through the root system.

Utilization of bioprocess intensification and the 'confinement phenomenon': When SRS-media contains bacteria for nitrogen fixation, it is possible that the BioProcess Intensification based on the 'confinement phenomenon' may also be utilized as part of the AgroProcess Intensification. However, this will require bacterium-selective pore size and pore wall surface chemistry. At present, we have not optimised these two variables for Rhizobium and hence it is not possible to attribute any function to the mechanism by which BioProcess Intensification takes place in micro-bioreactors made from SRS-media. In BioProcess Intensification (Akay et al., 2005), a constant flow of nutrient solution is present through the 3D culture media supported in a monolithic bioreactor. However, it is possible to obtain highly hydrophilic spongy/elastic SRS-media with desired pore size and surface chemistry in order further enhance the efficiency of the SRS-media.

Bacteria protection and growth promotion: Depending on the chemical/physical structure of the SRS-media, the penetration of the bacteria from the soil can be prevented or enhanced. Prevention of bacterial penetration into the SRS-media is partly through the low bacterial concentration outside the SRS-media and there is no active mechanism (such as forced convection) present in the soil to promote bacterial penetration. Only mechanism is through bacterial motility and division. Ingres and subsequent integration of bone cells into PolyHIPE Polymer used as graft showed that both pore and interconnect sizes and biochemical surface characteristics were important (Akay et al., 2002; Brebbia et al., 2011). Similarly, it is possible to obtain optimised polymers for root penetration and the integration of the SRS-media. Furthermore, SRS-media excludes large or less motile bacteria to enter into the bioactive SRS-media, therefore, the existing bacteria within the pores are protected from the penetration and subsequent colonisation by the other bacteria.

Bioactive SRS-media also acts as a sink for the sudden surge in toxins such as heavy metal ions (as ionic SRS-media is essentially an ion-exchange resin) or organic toxins (Akay et al., 2005; Galan and Valle, 2006). Sulphonated cross-linked polystyrene polymers used here are biphylic, that is, they adsorb both water and solvents. Therefore, SRS-media can take up both metal ions and organic toxin and subsequently release them gradually as the toxin levels in the environment decrease or they are metabolized through phytoremediation or by bacterial degradation.

Bacterial-plant symbiosis: Current results presented here indicate that even without the inclusion of bacteria into SRS-media, total biomass yield increases both for grass and pea. In the case of leguminous crop like pea, crop (pea pods) enhancement was only significant when the nitrogen fixing bacteria (Rhizobium) was present in the SRS-media. This was partly because there was no water stress. Results indicate that the pea plant receive more nitrogen through the SRS-media compared with the soil bacteria. This observation is further strengthened through the extensive presence of what appears to be plant exudates which provide plant/bacterium communication (Neumann and Romheld, 2000; Hatfield, 2005; Carvalhais et al., 2011). Under normal conditions in soilonly growth, these exudates will be present in small concentrations and can be washed away from the rootbacterium interface. Therefore, SRS-media enhances rootbacteria interactions.

\section{CONCLUSION}

The potential uses of nano-structured micro-porous polymers in agriculture were investigated. The purpose of this study was to investigate the scope and mechanism of the process. Therefore, suitable SRSmedia materials were developed to achieve a distinctive plant enhancement technique which could be rationalized within the framework of general Process Intensification and Miniaturization (PIM) technology. PolyHIPE Polymer is a novel micro-cellular polymer which can be either hydrophilic or hydrophobic, or indeed biphilic and has a well-defined and controllable micro-architecture for 3D-culture, essential for BioProcess Intensification and tissue engineering applications through the use of 'Confinement Phenomenon'. The processing conditions and chemical composition of the polymer were varied with the aim of enhancing surface area, water absorbency and root association. A spongy form of sulphonated 
PolyHIPE Polymer was developed for potential use as a soil additive and SRS-media to regulate water and fertilizer delivery and enhance root-bacterium-waternutrient interactions for AgroProcess Intensification due to the elimination of the random nature of the root, water, nutrient, microorganism interactions.

The experiments reported in this study were carried out in greenhouses. Further on-going studies include detailed understanding of the molecular mechanisms taking place within the SRS-media and experiments using growth cabinets so as to accelerate the project. As part of technology transfer activity, field trials are planned. These trials will also include pilot plant level production of sulphonated PolyHIPE Polymer.

SRS-media polymers can also be obtained as a product or waste from the intensified integrated ammonia and biorefinery processes disclosed recently (Akay 2011, 2012). These processes thus provide the link with energy, chemicals, water and agriculture. The use of PolyHIPE Polymer in ammonia and biofuel production enhances the sustainability of the AgroProcess Intensification.

\section{ACKNOWLEDGEMENT}

We are grateful to UK Engineering and Physical Sciences Research Council (EPSRC) for a PhD studentship for Dr David Burke and for funding this research in a consortium of 5 UK universities; Newcastle, Bristol, Oxford, Queen's Belfast and Warwick under the title of 'Intensified Integrated BioRefinery'. This project also benefited from the 7th European Framework Program Funding (CP-IP 228853-2 COPIRIDE). We are grateful to Mark Spinney (Syngenta, Jealott's Hill International Research Centre) for very helpful discussions.

\section{REFERENCES}

Abraham, J. and V.N.R. Pillai, 1996. Membraneencapsulated controlled-release urea fertilizers based on acrylamide copolymers. J. Applied Polymer Sci., 60: 2347-2351. DOI: $10.1002 /($ SICI) 1097 4628(19960627)60:13<2347::AIDAPP6>3.0.CO;2-E

Akay, G., 1998. Flow-induced phase inversion in the intensive processing of concentrated emulsions. Chem. Eng. Sci., 53: 203-223. DOI: 10.1016/S0009-2509(97)00199-1

Akay, G., S. Dawnes and V.J. Price, 2002. Microcellular polymers as cell growth media and novel polymers. Eur. Patent, 1183328.
Akay, G., M.A. Birch and M.A. Bokhari, 2004. Microcellular polyHIPE polymer supports osteoblast growth and bone formation in vitro. Biomaterials, 25: 3991-4000. DOI: 10.1016/j.biomaterials.2003.10.086

Akay, G., E. Erhan and B. Keskinler, 2005. Bioprocess intensification in flow-through monolithic microbioreactors with immobilized bacteria. Biotechnol Bioeng, 90: 180-190. DOI: 10.1002/bit.20376

Akay, G. and D.R. Burke, 2010. Synthetic symbiotic system as soil additives to deliver active ingredients through plant roots for enhanced plant and crop yield. PCT Patent Publication, WO/2010/040996.

Akay, G. and J. Vickers, 2010. Methods for separating oil and water. US Patent 7780854.

Akay, G., Z.Z. Noor, O.F. Calkan, T.M. Ndlovu and D.R. Burke, 2010. Process for preparing a functionalised PolyHIPE Polymer. US Patent, 07820729.

Akay, G., 2011. Ammonia production by integrated intensified processes. Int. Patent Appl., PCT/GB2011/051620.

Akay, G., 2012. Intensified integrated bio-refinery. British Patent Application, 1201086.4.

Akay, G., T. Pekdemir, A.S. Shokorfow and J. Vickers, 2012. Intensified demulsification and separation of thermal oxide reprocessing interfacial crud (THORP-IFC) simulants. Green Process. Synth. 1: 109-127. DOI: 10.1515/greenps-2011-0510

Allen, E.K., 1981. The Leguminosae, a Source Book of Characteristics, Uses, and Nodulation. 1st Edn., Univ of Wisconsin Press, Macmillan Publishers Ltd, London. ISBN-10: 0299084000, pp: 812.

Al-Nahidh, S and A.H.M. Gomah, 1991. Response of wheat to dual inoculation with VA-mycorrhiza and azospirillum fertilized with NPK and irrigated with sewage effluent. Arid Soil Res. Rehabil., 5: 83-96.

Ashraf, M., M. Ozturk and H.R. Athar, 2009. Salinity and Water Stress: Improving Crop Efficiency. Springer, Heidelberg,. ISBN-10: 1402090641, pp: 244.

Bahme, J.B. and N.M. Schroth, 1987. Spatial-temporal colonization patterns of a rhizobacterium on underground organs of potato. Phytopathology, 77: 1093-1100. DOI: 10.1094/Phyto-77-1093

Bashan, Y., 1998. Inoculants of plant growth-promoting bacteria for use in agriculture. Biotechnol. Adv., 16: 729-770. DOI: 10.1016/S0734-9750(98)00003-2

Benizri, E., E. Baudoin and A. Guckert, 2001. Root colonization by inoculated plant growth-promoting rhizobacteria. Biocontrol. Sci. Technol., 11: 557-574. 
Bissel, M.A., A. Rizki and A. Guckert, 2003. Tissue architecture: The ultimate regulator of breast epithelial function. Curr. Opin. Cell Biol., 15: 553562. PMID: 14644202

Bokhari, A.M., G. Akay, S. Zhang and M.A. Birch, 2005. A hybrid biomaterial combining the peptide hydrogel RAD 16-1 with PolyHIPE Polymer (PHP) enhances osteoblast and differentiation in vitro. Biomaterials, 26: 5198-5208.

Bokhari, M.A., M.A. Birch and G. Akay, 2003. Polyhipe polymer: A novel scaffold for in vitro bone tissue engineering. Adv. Exp. Biol., 534: 247254. PMID: 12903724

Bowers, J.H. and J.L. Parke, 1993. Colonization of pea (Pisum sativum L.) taproots by Pseudomonas fluorescens: Effect of soil temperature and bacterial motility. Soil Biol. Biochem., 25: 16931701. DOI: 10.1016/0038-0717(93)90172-8

Brebbia, C.A., M. Eglite, I. Knets, R. Miftahof and V. Popov, 2011. Environmental Health and Biomedicine. 1st Edn., WIT Press, Boston, ISBN: 1845645243 , pp: 512.

Burke, D.R., G. Akay and P. Bilsborrow, 2010. Development of novel polymeric materials for AgroProcess intensification. J. Applied Polymer Sci., 118: 3292-3299. DOI: 10.1002/app.32640

Cakmak, I., 2000. Tansley review No. 111-Possible roles of zinc in protecting plant cells from damage by reactive oxygen species. New Phytologist, 146: 185-205. DOI: 10.1046/j.1469-8137.2000.00630.x

Carvalhais, L.C., P.G. Dennis, D. Fedoseyenko, M.R. Hajirezael and R. Borriss et al., 2011. Root exudation of sugars, amino acids and organic acids by maize as affected by nitrogen, phosphorus, potassium and iron deficiency. J. Plant Nutr. Soil Sci., 174: 3-11. DOI: 10.1002/jpln.201000085

Chen, D.L and Z.L. Zhu, 2002. Nitrogen fertilizer use in China - Contributions to food production, impacts on the environment and best management strategies. Nutr. Cycl. Agroecosyst., 63: 117-127. DOI: 10.1023/A:1021107026067

Chu, M.S., Q. Zhu, Z.B. Huang and H.M. Li, 2008. Influence of potassium humate on the swelling properties of a poly(acrylic acid-co-acrylamide)/ potassium humate superabsorbent composite. J. Applied Polymer Sci., 107: 3727-3733. DOI: 10.1002/app. 27410

Conway, G. and G. Toenniessen, 1999. Feeding the world in the twenty-first century. Nature, C55-C58. PMID: 10591226

Eapen, D., M.L. Barrosso, G. Ponce, M.E. Campos and M.G.I. Cassab, 2005. Hydrotropism: Root growth responses to water. Trends Plant Sci., 10: 44-50. DOI: 10.1016/j.tplants.2004.11.004
El-Rehim, H.A.A., E.S.A. Hegazy and H.L.A. ElMohdy, 2004. Radiation synthesis of hydrogels to enhance sandy soils water retention and increase plant performance. J. Applied Polymer Sci., 93: 1360-1371. DOI: 10.1002/app.20571

Erhan, E., E. Yer, G. Akay, B. Keskinler and D. Keskinler, 2004. Phenol degradation in a fixed-bed bioreactor using micro-cellular polymerimmobilised Pseudomonas syringae. J. Chem. Tech. Biotechnol., 79: 195-206.

Fernandez-Escobar, R., M. Benlloch and J.M. GarciaNovelo, 2004. Effect of traditional and slowrelease $\mathrm{N}$ fertilizers on growth of olive nursery plants and $\mathrm{N}$ losses by leaching. Scientia Horticulturae, 101: 39-49. DOI: 10.1016/j.scienta.2003.09.008

Fesenko, A.N., N.A. Provorov, I.F. Orlova, V.P. Orlov and B.V. Simarov, 1995. Selection of Rhizobium leguminosarum bv. viceae strains for inoculation of Pisum sativum L. cultivars: Analysis of symbiotic efficiency and nodulation competitiveness. Plant Soil, 172: 189-198. DOI: 10.1007/BF00011321

Galan, M.A. and E.M.D. Valle, 2006. Chemical Engineering Trends and Developments. 1st Edn., John Wiley and Sons, Chichester, ISBN-10: 0470024992, pp: 400.

Glover, J.D., J.P. Reganold, L.W. Bell, J. Borevitz and E.C. Brummer et al., 2010. Increased food and ecosystem security via perennial grains. Science, 328: 1638-1639. DOI: 10.1126/science. 1188761

Halsall, D.M., 1993. Inoculation of wheat straw to enhance lignocellulose breakdown and associated nitrogenase activity. Soil Biol. Biochem., 25: 419429. DOI: 10.1016/0038-0717(93)90067-L

Hatfield, J.L., 2005. Encyclopedia of Soils in the Environment. 1st Edn., Elsevier Academic Press, Amsterdam, ISBN-10: 0123485304, pp: 2119.

Hessel, V., A. Renken, J.C. Schouten and J.I. Yoshida, 2009. Micro Process Engineering: A Comprehensive Handbook. 1st Edn., Wiley-VCH, Weinheim, ISBN-10: 3527315500, pp: 1412.

Jorgensen, U., T. Dalgaard and E.S. Kristensen, 2005. Biomass energy in organic farming - the potential role of short rotation coppice. Biomass Bioenergy, 28: 237-248. DOI: 10.1016/j.biombioe.2004.08.006

Khaosaad, T., J.M. Garcia-Garrido, S. Steinkellner and H. Vierheilig, 2007. Take-all disease is systemically reduced in roots of mycorrhizal barley plants. Soil Biol. Biochem., 39: 727-734. DOI: 10.1016/j.soilbio.2006.09.014 
Kucera, F. and F.J. Jancar, 1998. Homogeneous and heterogeneous sulfonation of polymers: A review. Polym. Eng. Sci., 38: 783-792. DOI: 10.1002/pen.10244

Kumar, V. and K.D.P. Nigam, 2012. Process intensification in green synthesis. Green Process. Synth., 1: 79-107. DOI: 10.1515/greenps-20110003

Leitner, D., S. Klepsch, G. Bonder and A. Schnepf, 2010. A dynamic root system growth model based on L-Systems Tropisms and coupling to nutrient uptake from soil. Plant Soil, 332: 177-192. DOI: 10.1007/s11104-010-0284-7

Lens, P. and P.N.L. Lens, 2005. Biofuels for Fuel Cells: Renewable Energy from Biomass Fermentation. 1st Edn., IWA Publishing, London, ISBN-10: 9781843390923, pp: 523.

Liu, M., R. Liang, F. Zhan, Z. Liu and A. Niu, 2007. Preparation of superabsorbent slow release nitrogen fertilizer by inverse suspension polymerization. Polym. Int., 56: 729-737. DOI: 10.1002/pi.2196

Liu, Y., M.F. Zhu and X.Y. Zhang, 2004. A study of the synthesis and properties of AM/AMPS copolymer as superabsorbent. Macromol. Mater. Eng., 289: 1074-1078. DOI: 10.1002/mame.200400154

Marschner, H., E.A. Kirkby and I. Cakmak, 1996. Effect of mineral nutritional status on shoot-root partitioning of photoassimilates and cycling of mineral nutrients. J. Exp. Botany, 47: 1255-1263. DOI: $10.1093 / j x b / 47 . S p e c i a l \_I s s u e .1255$

Mawatari, K., Y. Kazoe, A. Aota, T. Tsukahara, K.Sato and T. Kitamori, 2011. Microflow systems for chemical synthesis and analysis: Approaches to full integration of chemical process. J. Flow Chem., 1: 3-12. DOI: $10.1556 /$ jfchem.2011.00003

McKetta, J.J. Jr., 1995. Encyclopedia of Chemical Processing and Design. 1st Edn., CRC Press, ISBN-10: 0824726057, pp: 528.

Mittler, R., 2006. Abiotic stress, the field environment and stress combination. Trends Plant Sci., 11: 1519. DOI: $10.1016 /$ j.tplants.2005.11.002

Mohana, R.K., R.M. Padmanabha and M.Y. Murali, 2003. Synthesis of superabsorbent copolymers as water manageable materials. Polymer Int., 52: 768772. DOI: 10.1002/pi.1145

Mutch, L.A and J.P.W. Young, 2004. Diversity and specificity of Rhizobium leguminosarum biovar viciae on wild and cultivated legumes. Mol. Ecol., 13: 2435-2444. DOI: $10.1111 / \mathrm{j} .1365-$ 294X.2004.02259.x

Narkis, M. and N. Rosenzweig, 1995. Polymer Powder Technology. 1st Edn., J. Wiley, Chichester, ISBN: 0471938726, pp: 633.
Neumann, G. and V. Romheld, 2000. The release of root exudates as affected by the plant physiological status. Biochemistry.

Papendick, R.I., P.A. Sanchez and G.B. Triplett, 1976. Multiple Cropping. 1st Edn., ASA., Madison, WI, ISBN: 0891180451, pp: 378.

Puoci, F., F. Iemma, U.G. Spizzirri, G. Cirillo and M. Curcio et al., 2008. Polymer in agriculture: A review. Am. J. Agric. Biol. Sci., 3: 299-314. DOI: 10.3844/ajabssp.2008.299.314

Rhijn, V.P and J. Vanderleyden, 1995. The Rhizobiumplant symbiosis. Microbiol. Rev., 59: 124-142. PMID: 7708010

Santalla, M., J.M. Amurrio and A.M. Ron, 2001. Symbiotic interactions between Rhizobium leguminosarum strains and elite cultivars of Pisum sativum L. J. Agron. Crop Sci., 187: 59-68. DOI: 10.1046/j.1439-037X.2001.00502.X

Sbrana, C and M. Giovannetti, 2005. Chemotropism in the arbuscular mycorrhizal fungus Glomus mosseae. Mycorrhiza, 15: 539-545. PMID: 16133246

Smit, G., J.W. Kijne and B.J.J. Lugtenberg, 1986. Correlation between extracellular fibrils and attachment of Rhizobium leguminosarum to pea root hair tips. J. Bacteriol. 168: 821-827.

Solano, R.R., J.B. Maicas, M.T.P. Iglesia, J. Domenech and G.F.J. Manero, 2008. Systemic disease protection elicited by plant growth promoting rhizobacteria strains: Relationship between metabolic responses, systemic disease protection and biotic elicitors. Phytopathology, 98: 451-457. DOI: 10.1094/PHYTO-98-4-0451

Stacey, G.S., R.H. Burris and H.J. Evans, 1992. Biological Nitrogen Fixation. 1st Edn., Springer, New York, ISBN: 0412024217, pp: 943.

Stoop, W.A., N. Uphoff and A. Kassam, 2002. A review of agricultural research issues raised by the System Of Rice Intensification (SRI) from madagascar: Opportunities for improving farming systems for resource-poor farmers. Agric. Syst., 71: 249-274. DOI: $10.1016 /$ S0308$521 \mathrm{X}(01) 00070-1$

Takahashi, N.Y., A. Yamazaki, A. Kobayashi and H.H. Takahashi, 2003. Hydrotropism interacts with gravitropism by degrading amyloplasts in seedling roots of Arabidopsis and radish. Plant Physiol., 132: 805-810. PMID: 12805610

Tilma, D., K.G. Cassman, P.A. Matson, R. Naylor and S. Polasky, 2002. Agricultural sustainability and intensive production practices. Nature, 418: 671677. DOI: $10.1038 /$ nature 01014 
Uso, J.L., C.A. Brebbia and H. Power, 1998. Ecosystems and Sustainable Development. 1st Edn., Computational Mechanics Publications, Southampton, ISBN: 1853125024, pp: 678.

Walker, T.S., H.P. Bais, E. Grotewold and J.M. Vivanco, 2003. Root exudation and rhizosphere biology. Plant Physiol., 132: 44-51. DOI: 10.1104/ pp.102.019661

Waller, F., B. Achatz, H. Baltruschat, J. Fodor and K. Becker et al., 2000. The endophytic fungus Piriformospora indica reprograms barley to saltstress tolerance, disease resistance and higher yield. Proc. Nat. Acad. Sci., 102: 13386-13391. DOI: $10.1073 /$ pnas.0504423102
Wang, Y. and J.D. Holladay, 2005. Microreactor Technology and Process Intensification. 1st Edn., Oxford University Press, Oxford, ISBN-10: 9780841220324, pp: 444.

Wang, W., B. Vinocur and A. Altman, 2007. Plant responses to drought, salinity and extreme temperatures towards genetic engineering for stress tolerance. Planta, 218: 1-14. DOI 10.1007/s00425003-1105-5

Wirth, T., 2008. Microreactors in Organic Synthesis and Catalysis. 1st Edn., Wiley-VCH, Weinheim, ISBN-10: 3527318690, pp: 297. 